Rhode Island College

Digital Commons @ RIC

\title{
The Impact of Rapid Response Team Activation on Unplanned Transfers to the ICU
}

\author{
Erica Nelson
}

Follow this and additional works at: https://digitalcommons.ric.edu/etd

Part of the Nursing Commons

\section{Recommended Citation}

Nelson, Erica, "The Impact of Rapid Response Team Activation on Unplanned Transfers to the ICU" (2021). Master's Theses, Dissertations, Graduate Research and Major Papers Overview. 386.

https://digitalcommons.ric.edu/etd/386

This Major Paper is brought to you for free and open access by the Master's Theses, Dissertations, Graduate Research and Major Papers at Digital Commons @ RIC. It has been accepted for inclusion in Master's Theses, Dissertations, Graduate Research and Major Papers Overview by an authorized administrator of Digital Commons @ RIC. For more information, please contact digitalcommons@ric.edu. 


\section{THE IMPACT OF RAPID RESPONSE TEAM ACTIVATION ON UNPLANNED TRANSFERS TO THE ICU}

by

\section{Erica Nelson}
A Major Paper Submitted in Partial Fulfillment
of the Requirements for the Degree of
Master of Science in Nursing
in

The School of Nursing

Rhode Island College

2021 


\begin{abstract}
Rapid Response Teams (RRTs) were addressed by the Institute for Healthcare Improvement (IHI) as a means for improving inpatient hospital morbidity and mortality. There implementation was encouraged nationwide with the goal to decrease inpatient cardiopulmonary arrests, mortality rates and unplanned admissions to the Intensive Care Unit (ICU). The purpose of this systematic review was to evaluate the impact of RRTs on unplanned transfers to the ICU. A comprehensive literature review was performed using the PubMed database focusing on RRTs and unplanned ICU transfers. The Donabedian model was used as the theory for this review in conjunction with the PRISMA framework. Study specific data and data outcomes were extracted from individual studies and recorded in tables. Critical appraisal of the included studies was performed utilizing the CASP Checklist for cohort studies. Cross study analysis was then performed to compare outcomes of individual studies against one another in the form of a table. The findings of this systematic review addressed the impact of RRT on ICU admissions with varying outcomes in regards to number of patients admitted to the ICU after RRT review, APACHE scores, length of stay, and mortality. Results of this study address limitations of the identified research and recommendations and implications for the role of the advanced practice nurse.
\end{abstract}




\section{Table of Contents}

Background/Statement of the Problem .......................................................... 1

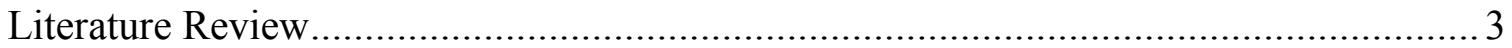

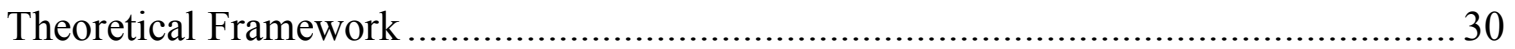

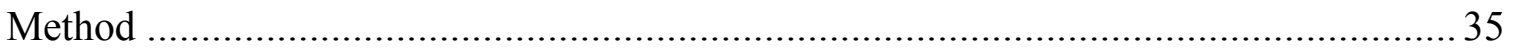

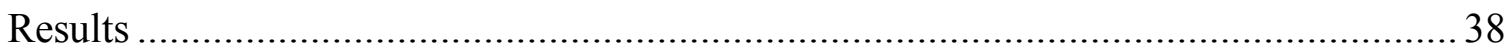

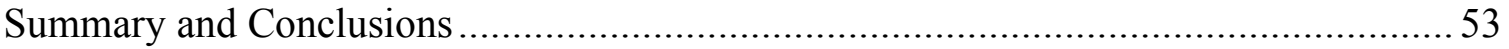

Recommendations and Implications for Advanced Nursing Practice ...........................5 57

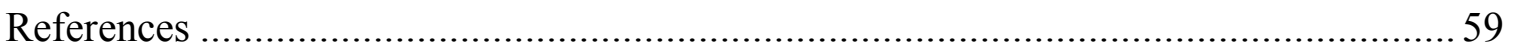

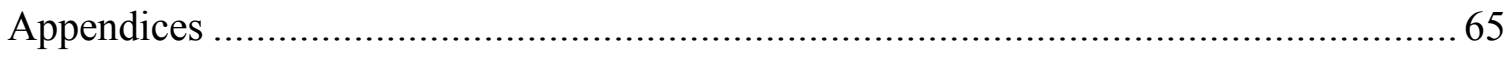


The Impact of Rapid Response Team Activation on Unplanned

Transfers to the ICU: A Retrospective Chart Review

\section{Background/Statement of the Problem}

In 2004, the Institute for Healthcare Improvement (IHI) announced a nationwide initiative, the 100,000 Lives Campaign, to address the growing concern regarding inpatient hospital morbidity and mortality (Institute for Healthcare Improvement, 2006). The goal was to provide hospitals across the nation the resources they needed to implement proven best practices that, in turn, would save 100,000 lives over 18 months. It was hypothesized that implementing some, or all, of the six recommended interventions by the IHI would have a positive impact on reducing morbidity and mortality (Institute for Healthcare Improvement, 2006). One of these six interventions addressed the importance of implementing Rapid Response Teams (RRTs) to facilitate prompt medical intervention at the first signs of patient deterioration. The 100,000 Lives Campaign proved to be successful, motivating the IHI to further implement the 5 Million Lives Campaign in 2006 (Institute for Healthcare Improvement, 2006). Notably, the Joint Commission addressed the need for early recognition of patient deterioration and improved communication by incorporating RRTs into their 2008 National Patient Safety Goals (Revere \& Eldridge, 2008).

Rapid Response Teams are thought to reduce inpatient hospital mortality, cardiopulmonary arrests and unplanned transfers to the Intensive Care Unit (ICU). Despite ongoing improvements in healthcare nationally and internationally, to establish RRTs, there continues to be conflicting evidence on the benefit of these teams to patient outcomes. Additionally, data gathered from the National Hospital Discharge Survey, 
2000-2010, states that approximately one-third of the 2.5 million deaths in the United States occurred in general hospitals. Although there was an $8 \%$ decrease in the number of hospital deaths from the year 2000 to 2010 , there continues to be room for improvement. Current research focuses more on outcome assessment of mortality and cardiopulmonary arrest and less on unplanned transfers to the ICU.

The purpose of this study was to investigate whether RRTs have an impact on unplanned transfers to the ICU. A systematic review was performed in order to further explore this topic and provide a means for dissemination of the most recent literature to guide the development and improvement of RRTs.

Next, the review of literature will be presented. 


\section{Literature Review}

The data bases searched included CINAHL Plus with Full Text, PubMed, and Google Scholar using the keywords: rapid response team, rapid response system, medical emergency team, mortality rates, cardiopulmonary arrest, ICU admission, activation criteria, activation barriers and patient outcomes. Articles were chosen for review based off of the following criteria: Full text available, English language, dated from the years 2000-2020.

\section{Rapid Response Team History and Development}

DeVita et al. (2014) report that the idea of a Medical Emergency Team (MET) was initially developed in the 1990s in Australia. The evidence suggests that often patients exhibit abnormalities in vital signs prior to sustaining an in-hospital cardiac arrest (IHCA) (DeVita et al., 2014). In response to this development, the concept of a MET was developed. A MET was different from a cardiac arrest team or "code blue" team in that the goal was to provide interventions that would prevent further deterioration and adverse clinical outcomes (Agency for Healthcare Research and Quality, 2019). The presentation of vital sign abnormalities or other signals of decompensation triggered the rapid response of physicians to the bedside to deliver expertise and skills to prevent further decline (DeVita et al., 2014). This new initiative bypassed the traditional hierarchical approach to prevent a potential further delay in care.

Over time, there have been modifications to the original model of MET. This includes modifications of activation criteria including the involvement of staff concern, changes in team composition, the utilization of early warning scoring systems, active patient rounding by MET members to assess at-risk patients, the utilization of MET in 
pediatrics, as well as identifying potential preventable gaps in care by the use of adverse events (DeVita et al., 2014). The idea behind METs began to grow and was adapted in other countries making its way to the United States in 2003 (Padilla et al., 2018).

In 2004, The 100,000 Lives Campaign included the Rapid Response Systems as one of their six interventions to improve morbidity and mortality in the United States (Institute for Healthcare Improvement, 2006). Internationally, there are now different models of teams including the MET, Rapid Response Teams (RRTs) and Critical Care Outreach (CCO) (Agency for Healthcare Research and Quality, 2019). Despite variations in models regarding personnel involved, the main goal remains the same; to improve patient outcomes including the prevention of cardiac arrest, death, and unplanned transfers to the ICU. In an effort to provide unification of these terms, DeVita et al. (2006) advocated for the use of the term Rapid Response Systems (RRSs) at the 2006 consensus conference.

\section{Rapid Response Team Composition}

Much research has focused on the assessment of the effect RRTs on patient and organizational outcomes, but few have provided descriptive information on the components of these systems throughout multihospital organizations (Stolldorf and Jones, 2015). For example, Stolldorf and Jones (2015) aimed to describe the differences in RRT programs amongst hospitals and health centers by surveying hospital members. Those surveyed included hospital administrators, CNOs, COOs, directors, nurse managers, patient safety officers and quality experts. Using a cross-sectional study design, the research team developed a 40-item survey that aimed to gather self-reported data to assist in examining the sustainability of RRTs. The survey variables were categorized into 
organizational characteristics, RRT characteristics, and RRT-related outcomes. Out of the 56 organizations invited to participate in the survey, 31 responded for a response rate of 58\% (Stolldorf \& Jones, 2015). These organizations consisted of academic health centers $(19 \%)$, community hospitals $(71 \%)$, corporate health systems $(6 \%)$, and one critical access hospital (3\%) (Stolldorf \& Jones, 2015).

In evaluating Rapid Response System (RRS) characteristics, Stolldorf and Jones (2015) compared the afferent, efferent, process improvement and administrative oversight components. The afferent component of RRS is identified as the event detection and trigger to initiate the team whereas the efferent component consists of the RRT. It was found that registered nurses throughout all 31 hospitals could activate the RRT in addition to other hospital staff members in 30 hospitals, families in 19 hospitals, and patients in 17 hospitals (Stolldorf \& Jones, 2015). Comparatively, in 12 hospitals, only RNs and other hospital staff could activate RRTs (Stolldorf \& Jones, 2015). The efferent component varied greatly throughout organizations in regard to how many RRTs the facility had, the number of staff on the team and who the team leader was whether a doctor or nurse. The majority of teams had an Intensive Care Unit (ICU) RN and Respiratory Therapist (RT), with 71\% of hospital RRTs being led by an RN (Stolldorf \& Jones, 2015). Additionally, ten of the hospitals provided debriefing after RRT activation and thirteen hospitals followed with patients within 24 hours after RRT call was initiated. Of the 31 hospitals, only seven performed both interventions. In addressing components of RRT safety and process improvement and oversight, twelve hospitals included RRT evaluation, where staff members evaluated the RRT, RRT members received feedback from their leaders on performance, and outcomes of RRT were shared with staff 
(Stolldorf \& Jones, 2015). The majority of hospitals had an oversight committee specific to RRT which is important in evaluating the process for strengths and weaknesses for quality improvement.

Stolldorf and Jones (2015) demonstrated that large teaching hospitals were more strongly associated with increased number of RRTs available to respond to calls as well as having MD-led RRT that followed a specific model and provided debriefing. Data on RRT outcomes was lacking as respondents had the option to skip questions resulting in lack of consistent answers.

\section{Indications for Rapid Response Team Activation}

Rapid Response Teams are activated when a patient shows early signs of decompensation in order to prompt immediate treatment. Activation of the RRT is guided by a set of institution specific criteria also referred to as calling criteria; signs of patient deterioration that trigger a healthcare professional or, in some institutions, a family member to call for further assistance to the bedside. These criteria include changes in vital signs, neurological, cardiac, or respiratory impairment, as well as overall nursing concern or worry.

The 'worried' criterion is one of the most commonly utilized reasons for activation of a MET. In addition to assessing patients for objective signs of deterioration, worried criteria allow staff to utilize intuition and clinical judgment to call a MET.

Santiano et al. (2009) performed a descriptive study of MET calls throughout six hospitals in Australia over a 12-month period. The aim of their study was to compare outcomes of calls initiated from objective versus worried criteria. Santiano et al. (2009) 
also aimed to identify underlying objective reasons that may not have been apparent to staff at the time when they called a MET based off of feeling worried.

The researchers performed data extraction from the MET database for the six participating hospitals. The primary reason for MET call is documented in the database and includes a free text format for activation based off of worried criterion. The free text entries were content analyzed and coded under four main headings: Airway, Breathing, Circulation and Neurology (Santiano et al., 2009). Additional categories were a deterioration in vital signs and other, to cover calls related to chest pain, syncope, pain, or inadequate level of care (Santiano et al., 2009).

Of the 3,189 MET calls throughout the six hospitals, 29\% were due to staff being worried (Santiano et al., 2009). Further analysis revealed that half, or 51.7\%, of the worried calls were related to objective findings that could be classified as Airway, Breathing, Circulation or Neurology (Santiano et al., 2009). The most significant underlying cause was breathing, or respiratory related $(35.2 \%)$ and the second most common was circulatory problems (12.2\%) (Santiano et al., 2009). When the cause of worry could not be categorized to objective data they were categorized as other. Fiftyeight $(26.7 \%)$ of these were related to chest pain and $16.1 \%$ were due to syncope or collapse (Santiano et al., 2009). In assessing patient outcomes after a worried MET call, Santiano et al. (2009) found that $75.1 \%$ of patients remained on their unit and $18.6 \%$ were transferred to the ICU. This is compared to calls initiated based on objective criteria where $70.7 \%$ of patients stayed on their unit and $17.1 \%$ were transferred to the ICU (Santiano et al., 2009). Comparatively, 1.1\% of patients experienced a cardiac arrest immediately after worried MET calls in contrast to $7.6 \%$ of patients who experienced a 
cardiac arrest after a MET call due to objective criterion (Santiano et al., 2009). This indicates that staff felt empowered to advocate for their patients and to activate a MET when they are were concerned about the stability of their patients but could not pinpoint an objective cause (Santiano et al., 2009).

A study by Chen et al. (2010) aimed to compare activation criteria between hospitals with and without an established medical emergency team (MET). To guide their study, the researchers utilized a cluster randomized controlled trial approach. Chen et al. (2010) hypothesized that emergency team activation would be affected by the presence of a MET system, type of hospital, type of unit, and time of day. After data was obtained, it was analyzed using Stata 9.2 to assess for statistical significance.

The research performed by Chen et al. (2010) revealed differences between hospitals with and without a MET system related to activation criteria. Hospitals that did not have a formal MET system in place, activated an emergency team most often for a decrease in Glasgow Coma Scale (GCS) by 2 or more points (45.6\%), abnormalities in pulse rate $(34.8 \%)$ or respiratory rate $(33.1 \%)$, in addition to staff being 'worried' or having no specified reasoning (30.5\%) (Chen et al., 2010). In hospitals that had a MET, reasons for activation included staff being 'worried' or no specified reason (39.3\%), a decrease in GCS (32.1\%), and abnormalities in respiratory or pulse rate $(21 \%)$ (Chen et al., 2010). It was found that MET hospitals were 35 times more likely to activate the MET due to staff being 'worried' (Chen et al., 2010). Additionally, MET hospitals were found to activate a call for only one reason $55.8 \%$ of the time. Hospitals without a MET triggered the emergency team for only one reason $31.3 \%$ of the time and were also more 
likely to call due to 3 or more triggers present at once $20.8 \%$ of the time (Chen et al., 2010).

The results reported by Chen et al. (2010), indicate that hospitals with an established MET were more likely to activate the emergency team at early signs of patient deterioration. This was evidenced by them utilizing the staff 'worried' criteria as well as more commonly activating when only one trigger was present. Activating the emergency team when there may not be specific physiologic instability allows for earlier bedside intervention.

Jones et al. (2012) aimed to assess staff composition of RRTs, hours of operation, differences in calling criteria, and if hospitals obtained additional funding for the implementation of RRT throughout Australia. The study was coordinated by the Australian and New Zealand Intensive Care Society Centre for Outcome and Resource Evaluation (ANZICS-CORE) with funding provided by the Australian Commission for Safety and Quality in Health Care (ACSQHC). One-hundred and eight Australian hospitals were identified as being ICU-equipped from the 2007/2008 annual ANZICSCORE survey. They were invited to participate in the study via email with a response rate of $36.1 \%$, which included 39 out of 108 hospitals (Jones et al., 2012). Analysis of descriptive data revealed that all participating hospitals have an RRT that operates 24 hours per day, 7 days per week (Jones et al., 2012).

A great deal of variation was found in participating hospitals regarding staff composition and calling criteria. It was found that 38 out of 39 hospitals had a physicianled RRT, which included an ICU fellow as part of the team in 29 hospitals and internal 
medicine fellows as part of the team in an additional 27 hospitals (Jones et al., 2012). Thirty teams consisted of an ICU nurse with the rest including either a coronary care nurse, emergency department nurse or ICU nurse consultant (Jones et al., 2012). The study by Jones et al. (2012) identified seven hospitals where the most senior team member was unlikely to be able to perform advanced airway skills. The greatest variability existed among specific calling criteria. The majority of hospitals, $77.8 \%$, utilized a structured calling criteria chart that emphasized categories of Airway, Breathing and Circulation though the chart and thresholds varied amongst institutions (Jones et al., 2012). All hospitals identified upper and lower limits for respiratory rate, thirty hospitals specified pulse oximetry saturation of oxygen ( $\mathrm{SpO} 2)$, and fifteen hospitals identified cardiac arrest as a calling criterion (Jones et al., 2012). Additionally, all participating hospitals included low systolic blood pressure as criteria and 34 of 36 hospitals identified a low heart rate criterion (Jones et al., 2012). Results also showed that 24 out of 36 hospitals identified a heart rate greater than $140 \mathrm{bpm}$ as calling criterion (Jones et al., 2012). A change in conscious state was reason to initiate a RRT with criterion varying from a decrease in GCS of greater than 2 points, a decrease in conscious level, seizure, stroke, agitation/delirium, or decreased sensation or limb strength (Jones et al., 2012). Other criterion for RRT activation included decreased urinary output, staff feeling worried or concerned, uncontrolled pain, no patient response to treatment, impaired timeliness of physician assessment, low blood sugar, uncontrolled bleeding, and electrolyte abnormalities (Jones et al., 2012).

Variations amongst institutions regarding calling criteria was alarming as staff are reliant on such criteria to initiate RRTs. The study by Jones et al. (2012) had limitations 
including a small sample size and the majority of hospitals being from one region of Australia which reduces the generalizability of the study. Despite a low response rate, Jones et al. (2012) were able identify inconsistencies of calling criteria which allows for future research opportunities concerning how these variations impact patient interventions and outcomes as well as if any specific calling criteria is superior to allow for standardization throughout hospitals.

As Jones et al. (2012) identified, activation criteria for METs include a range of objective information including vital sign changes and change in mental status. In addition to objective assessment findings, some hospitals provide the opportunity for staff to use their intuition when they feel something is not right, to activate a MET. This assessment is referred to as staff feeling worried, concerned, or the overall feeling that something is not right (Jones et al., 2012). Nursing intuition is a concept that is hard to define but can be referred to as the connection that nurse's make with their patient's wellbeing incorporating senses, emotions and clinical experience (Raymond et al., 2019).

Raymond et al. (2019) aimed to further assess what clinical findings may actually define the term worried, when METs are activated due to staff worry. The study took place from July 1, 2010 to December 31, 2015 within a single 260 bed acute teaching hospital. When an MET is called, data was collected and entered into a quantitative risk assessment tool used by the hospital termed RiskMan (Raymond et al., 2019). Raymond et al. (2019), extracted data from all calls activated during the identified time period and entered it into Microsoft Excel for quantitative analysis. 
The hospital where the study by Raymond et al. (2019) took place identified adult MET call activation criteria as:

Respiratory rate $<9$ or $>35$, oxygen saturation $<85 \%$ or new drop in $\mathrm{SaO} 2<90 \%$, severe respiratory distress, apnea, cyanosis, stridor/upper airway obstruction, systolic $\mathrm{BP}<90 \mathrm{mmHg}$, pulse rate $<40$ beats/minute or $>140$ beats/min, urine output $<120 \mathrm{ml}$ in 4 hours, sudden decrease in conscious state or repeated or prolonged seizures and lastly, deterioration in medical condition requiring urgent medical review that may not meet above stated criteria (p. 379).

The top three reasons for MET activation were low blood pressure (SBP <90), low Glasgow Coma Scale (GCS), and staff worry (Raymond et al., 2019). Upon further analysis, 260 of the 344 calls activated for worry had a secondary cause identified (Raymond et al., 2019). These indicators, in descending order, included: not quite right, cardiac reason including chest pain or ECG abnormalities, low oxygen saturation or breathing problems, unresponsive, or other (Raymond et al., 2019). A range of clinical findings were found to be related to MET activation for not quite right and other. These included: adverse drug reactions commonly associated with a chemotherapy drug called Docetaxel, neurological changes including seizures, bleeding, and blood pressure changes, changes in mental health state including anxiety, agitation, pain, metabolic changes and fever (Raymond et al., 2019).

Raymond et al. (2019) identified that the majority of MET activations for nurses feeling worried were ultimately related to abnormal clinical finding that perhaps were not obvious to the staff. Due to these results, the researchers state that calling a RRT based 
only on nursing intuition is not a justifiable conclusion as they were able to identify an objective clinical finding that ultimately could be related to the RRT activation. Despite Raymond et al. (2019) reporting that nursing intuition is not a specific enough reason for calling a RRT, they continue to support this calling criteria as it allows for nurses to autonomously act on behalf of their concern and better judgement to receive timely interventions for unexpected changes that may not be specifically identified in activation criteria. Limitations to this study included the presence of incomplete chart documentation that led to the exclusion of cases for data extraction. This study was performed in one hospital which does not allow for generalizability especially considering different hospitals have developed their own set of activation criteria.

\section{Barriers to Activation}

To assist in identifying attitudes and barriers towards a MET amongst nurses and physicians, Radeschi et al. (2015) performed a multicenter survey using an anonymous questionnaire. The study aimed to identify if attitudes and barriers were influenced by previous experience in activating a MET and/or if they had participated in a MET educational program. Additional variables that were measured were whether or not attitudes and barriers were influenced by professional roles, seniority and type of unit they worked on (Radeschi et al., 2015). The MET educational program, titled METal (medical emergency team alert), was aimed at educating healthcare professionals that do not work in critical care areas about activating a MET. Education included patient characteristics, assessment, criteria for activation, how to initiate a call, and teamwork (Radeschi et al., 2015). Radeschi et al. (2015) utilized a modified version of a questionnaire developed by Jones et al. (2006), titled "Survey of nurses attitudes to the 
MET'. This is a 17-item Likert-type questionnaire aimed to assess nurses' understanding of the reason behind the use of MET as well as potential barriers to using it (Jones et al., 2006). Radeschi et al. (2015) added more specific questions to the survey regarding the METal. The responses to questions were based on the Likert-scale from 1, strongly disagree, to 5, strongly agree.

Paper questionnaires were delivered to medical and nursing staff with a $79.6 \%$ response rate (Radeschi et al., 2015). The respondents consisted of 1278 nurses and 534 medical doctors (Radeschi et al., 2015). Of these respondents, 859 nurses and 194 doctors completed the METal course (Radeschi et al., 2015). Fifty-four percent of responders identified that participating in the METal enhanced their skills in managing unstable patients (Radeschi et al., 2015). Results of the survey indicated that $82 \%$ of respondents found the MET to be helpful in preventing cardiac arrest in deteriorating patients (Radeschi et al., 2015). Seventy-seven percent of participants agreed that MET interventions did not increase their workload, $85 \%$ found METs to be useful in improving their skills of managing deteriorating patients, and $75 \%$ reported that it added value to their own professional roles (Radeschi et al., 2015). In addressing barriers to initiating a MET, $5 \%$ identified being reluctant for fear of being criticized and $12 \%$ for having made an inappropriate call (Radeschi et al., 2015). Additional results revealed that $21 \%$ would not have called a MET if a patient looked well despite fulfilling calling criteria and $62 \%$ reported not calling an MET without called the covering doctor first (Radeschi et al., 2015). The small number of respondents who identified fear of criticism as a barrier to calling a MET was reassuring, but further education and research should be done 
regarding waiting to call the covering physician before initiating a MET as it can result in delay of interventions.

A descriptive correlational study by Jackson et al. (2016) was conducted to examine nurse's beliefs and attitudes that influence their decision to activate a RRT. A 17-item Likert-style survey, Nurses' Attitudes Toward the MET designed by Bagshaw et al. (2010) was administered to 342 nurses in a community hospital (Jackson et al., 2016). A response rate of $48 \%$ was achieved and data results were analyzed using the SPSS statistical program (Jackson et al., 2016).

Results from the survey revealed that the majority of nurses found the use of a RRT helpful in preventing cardiac and respiratory arrest, assisted in preventing a minor problem from escalating and was helpful in managing sick patients (Jackson et al., 2016). The majority of respondents felt a RRT provided them with assistance in managing their decompensating patients and few felt a RRT was necessary due to inadequate nursing or doctor management (Jackson et al., 2016). The majority of nurses did not have a fear of criticism or that they were not looking after their patient well enough when it came to activating a RRT. In addressing additional barriers to activation, nurses disagreed that a RRT would increase their workload (80.1\%) or that it would reduce their skills in managing sick patients (96.9\%) (Jackson et al., 2016). Surprisingly, $71.2 \%$ of nurses reported that they would contact the covering doctor before initiating a RRT and if they could not get in touch with the doctor, $78.6 \%$ would activate the RRT. Over $60 \%$ of nurses reported that they would activate a RRT if their patient met criteria but looked well as well as if their patient's vital signs were normal but the nurse was concerned for other reasons (Jackson et al., 2016). 
Additional analysis revealed a negative relationship between years of experience as a nurse and barriers to activating a RRT. Fear of criticism from other health care providers as well as fear that they were not assessing and managing their patient appropriately was more likely among newer nurses (Jackson et al., 2016). There was also a relationship between newer nurses and the concern that a RRT would increase their workload and impact their development of skills to manage sick patients (Jackson et al., 2016). This evidence is important in ensuring that nurses with less experience are supported in the workplace to prevent fears and anxieties as well as prevent further patient decompensation from delay in treatment.

The idea behind RRSs is to implement interventions at the bedside when patients exhibit signs of clinical deterioration; the earlier the better. Research has demonstrated that nurses fail to activate the RRS or have a delay in activation without clear reasoning (Padilla et al., 2018). Padilla et al. (2018) performed a systematic review in order to identify barriers nurses face in activating a RRS. After a comprehensive literature search and article exclusion, a total of 8 studies were used for this systematic review (Padilla et al., 2018). The 8 studies were all descriptive cross-sectional with an evidence level of III on the JHNEBP Rating Guide and were conducted in the United States, Canada, Greece, Italy, and Australia (Padilla et al., 2018). The methodology utilized by Padilla et al. (2018) was Preferred Reporting Items for Systematic Reviews and Meta-analysis (PRISMA). Padilla et al. (2018) further utilized The John Hopkins Nursing EvidenceBased Practice (JHNEBP) model to rate study strength and quality.

After study analysis, Padilla et al. (2018) identified four themes that related to nurses' barriers to activating RRSs. The four themes included were: RRS activator- 
responder interaction, physician influence, nurse education, and nurse experience (Padilla et al., 2018). Related to RRS activator-responder interaction, four studies showed that nurses felt reluctant to activate a RRS due to fear of being criticized for activating the RRS (Padilla et al., 2018). Additional studies revealed that nurses felt they would not be treated with respect from the RRT and that activating the RRT meant they were unable to manage their patient (Padilla et al., 2018). Interestingly, one study revealed that $40 \%$ of nurses felt that activating a RRS would increase their workload (Padilla et al., 2018). Also of note, Padilla et al. pointed out that nurses felt as though they should notify the covering physician before activating the RRS regardless of patient deterioration. One study revealed that $7.5 \%$ of nurses activated a RRS when they felt as though the covering physician was mismanaging the patient's condition (Padilla et al., 2018). Level of nursing education was also shown to correlate to RRS activation. Those who graduated from a 4year program were able to more accurately identify scenarios that justified a RRS while Associate degree prepared nurses were more likely to seek assistance from another nurse or physician (47\% compared to $23 \%$ for bachelor's degree) (Padilla et al., 2018). Other than level of education, there was a positive relationship between nurses with advanced resuscitation training and likelihood to activate a RRS (Padilla et al., 2018). Alarmingly, one study revealed that $50 \%$ of nurses reported inadequate education regarding RRS or that they had not received any education at all (Padilla et al., 2018). Lastly, conflicting evidence was found concerning nursing education. Two studies revealed that nurses with less experience activated the RRS more than nurses with more experience (Padilla et al., 2018). Conversely, three studies reported that nurses with more experience actually activated the RRS more frequently with hypothesis that they may be less intimidated by 
RRS members and may also find more value in the team's input (Padilla et al., 2018).

The authors point out that newer nurses may call the RRS less frequently, as they fear it would hinder their skill development in managing sick patients. Additionally, newer nurses may tend to feel less sure of their clinical knowledge, and sensing when it is necessary to activate the team (Padilla et al., 2018). In their systematic review, Padilla et al. (2018) are able to identify many potential causes of barriers to RRT activation by nurses. It is important for healthcare institutions to individually evaluate their RRT effectiveness and address institution specific barriers to encourage increased utilization and prevent patient deterioration.

\section{Rapid Response Teams and Cardiopulmonary Arrest}

Several factors have been reported in relation to achieving resuscitation and improving survival to discharge. These factors include witnessed arrest, early initiation of intervention, return of spontaneous circulation within 20 minutes, young age, time of day, and continuous patient monitoring (Galhotra et al., 2007). Even with implementation of some or all of these factors, there continued to be poor rates of survival to discharge, highlighting the importance of being able to identify patient deterioration early to prevent cardiopulmonary arrests. Rapid response systems (RRS) were implemented to assist in early detection of patient deterioration to promote early intervention. One barrier to the utilization of RRSs is proper patient monitoring and early activation. The purpose of Galhotra et al.'s (2007) study was to identify the incidence, outcome, and avoidable causes of cardiopulmonary arrests inpatient. This retrospective observational study took place in a 730-bed tertiary care hospital in Pittsburgh, PA where a RRS had been established since 1989. Characteristics of the RRS included: being led by a critical care 
medical faculty member, a critical care medicine fellow, two ICU nurses, and two respiratory therapists. The RRS can be activated by anyone including staff, patients, or families, anywhere in the hospital, anytime of day.

Galhotra et al. (2007) gathered information from the hospitals' code database to identify inpatient cardiopulmonary arrests from January 1, 2005 to December 31, 2005. Data was extracted from a physician at the hospital who reviewed each event with the Hospital Code Review Committee. This review prompted discussions where categories for identification were chosen. The events were identified as predictable if there was clear evidence of patient deterioration 6 hours prior to the arrest or potentially avoidable if one of four further identified criteria were met and if they had been avoided would have prevented an arrest (Galhotra et al., 2007). These four potentially avoidable criteria were: failure to adhere to hospital policy like DVT prophylaxis, delay in RRS activation or calling for help, inadequate monitoring, or a complication of a procedure or surgery (Galhotra et al., 2007). In addition to predictability and potentially avoidable, events were further classified by how the patient was monitored: unmonitored, monitoring, or ICU.

Results found that there were 1942 RRS activations throughout the year with 111 being cardiopulmonary arrests (Galhotra et al., 2007). Twenty-two of the arrests occurred in unmonitored settings, 52 in monitored settings, and 30 in the ICU (Galhotra et al., 2007). There was no significant relationship between increasing predictability and decreasing potentially avoidable arrests with increased patient monitoring. Of the 111 arrests, 26 patients survived to hospital discharge; there was no significant differences in survival to discharge amongst the three settings (Galhotra et al., 2007). Further assessment of events revealed that $19(18 \%)$ of the cardiopulmonary arrests that occurred 
were potentially avoidable (Galhotra et al., 2007). The three most common reasons identified were: failure to adhere to hospital policy, inadequate monitoring, or delay in RRS activation (Galhotra et al., 2007). Six of the potentially avoidable arrests occurred in unmonitored beds despite four patients having indication to be in a monitored setting (Galhotra et al., 2007). Two of the events were related to lack of prophylactic anticoagulation for DVT/PE by care providers (Galhotra et al., 2007). Additionally, three patients that were in monitored settings and met established criteria for RRS activation, suffered from delay in activation from 20 minutes to one hour (Galhotra et al., 2007). Limitations to this study included the subjective judgment of classifying events by the code review team. Although this study did not discuss specific findings regarding decrease rates in cardiopulmonary arrests in hospitalized patients with implementation of RRS, it addressed potentially avoidable causes of said events. Identifying these events supports the hypothesis that adhering to hospital policy, increasing frequency if inpatient monitoring, and activating RRS early may have a positive impact on outcomes of cardiopulmonary arrests in the hospital setting.

In the work of Davis et al. (2015), investigators instituted a unique RRT model where the unit charge-nurse played an important role in high-risk patient identification. Davis et al. (2015) included two urban university hospitals with an approximate total of 500 medical/surgical beds in their study from the fiscal year June 2005 to June 2011. These hospitals initiated a RRT in November 2007 that was compromised of a dedicated critical care nurse, respiratory therapist, and unit specific charge nurse (Davis et al., 2015). Although the unit charge nurse did not play a role in first responder, they were 
part of the afferent system of rounding on at-risk patients on their unit to assist the bedside nurse in identifying early decompensation (Davis et al., 2015).

Linear regression and Pearson correlation coefficient were utilized to analyze data obtained from the electronic patient care record of all inpatient Code Blue and RRT activations (Davis et al., 2015). Results indicated a statically significant $(p<0.0001)$ decrease in non-ICU cardiopulmonary arrests from pre-implementation of RRT in 2006 (2.7 arrests per 1,000 discharges) as compared to post-implementation (1.1 arrests per 1,000 discharges) (Davis et al., 2015). Though there was a significant decrease in nonICU cardiopulmonary arrests, the incidence of cardiopulmonary arrests remained unchanged (Davis et al., 2015). Between the years 2005 and 2011 there were 247 nonICU cardiopulmonary arrests and a total of 1729 RRT calls from 2007 to 2011 (Davis et al., 2015). Davis et al. (2015), reported an inverse relationship between the number of Code Blue activations and RRT activations on units after analyzing year-over-year data. Additionally, there was a significant decrease $(p<0.001)$ in overall hospital mortality from 2006 to 2011 (2.12\% to $1.74 \%$ respectively) (Davis et al., 2015). Although this study was not a randomized prospective trial and lacks internal validation, it demonstrates a significant inverse relationship between RRT activations and incidence of cardiopulmonary arrest through four years of data analysis (Davis et al., 2015).

Angel et al. (2016) performed a retrospective study in a 636-bed academic hospital to assess how a well-functioning RRT impacts the incidence of cardiac arrests outside the ICU. Data was collected from all adult medical-surgical inpatients who had a RRT from January 2005 to December 2006 during the immediate phase after RRT initiation and again from January 2007 to December 2008 to assess outcomes after the 
RRT had been relatively well-established (Angel et al., 2016). A total of 273 adult patients were identified who had experienced cardiac arrest outside the critical care area (Angel et al., 2016).

Angel et al. (2016) utilized the American Society of Anesthesiologists (ASA) score to measure the level of clinical illness between the two time periods. There was a decrease in cardiac arrests from 2007-2008 despite an increase in hospital census with 102 occurrences in the last two years compared to 171 in the first two years of the study (Angel et al., 2016). Data analysis demonstrated statistical significance related to mean ASA scores between the two time periods: 3.7 in 2005-2006 and 3.5 in 2007-2008 ( $p=0.003)$ (Angel et al., 2016). The authors further suggest that statistical significance in ASA scores between the two periods may be related to the well-established RRT and their improved ability to identify rapidly deteriorating patients to initiate interventions before cardiac arrest. This study did not demonstrate statistical significance in mortality of patients suffering from cardiac arrest, thus emphasizing the importance of thorough patient assessment and prompt interventions at early signs of decompensation (Angel et al., 2016).

\section{Rapid Response Teams and Hospital Mortality}

Beitler et al. (2011) identified that previous research has shown conflicting results in hospital mortality rates after RRT implementation that can be correlated to underutilization of RRT as well as delay in activation. The researchers hypothesized that implementing a RRT that emphasized the importance of clinical judgment as an activation criterion would support nursing empowerment as well as increase utilization and improve mortality outcomes (Beitler et al., 2011). In addition to determining the 
effect of RRT on hospital-wide mortality, Beitler et al. (2011), examined the impact on out-of-ICU mortality and out-of-ICU cardiopulmonary arrests utilizing a cohort design with historical controls. An 809-bed tertiary public teaching hospital in New York City was chosen as the research site from 2003-2008 (Beitler et al., 2011).

During the education phase of orienting staff to RRT, Beitler et al. (2011), strongly emphasized the utilization of clinical judgement. Staff were encouraged to activate a RRT at any sign of clinical deterioration without fear of being reprimanded. Specific vital-signs criteria were also identified to prompt a RRT call. Poisson regression was utilized to calculate the relative risk and confidence intervals to determine if the implementation of a RRT correlated with reductions in mortality and cardiopulmonary arrest codes (Beitler et al., 2011). Beitler et al. (2011) collected data on all patients including demographics, mortality and case-mix index to measure for illness severity. Results indicated that patients in the post-RRT group had a higher acuity of illness according to the case-mix index (Beitler et al., 2011). Regardless of the higher acuity of illness, hospital-wide mortality was shown to have a significant decrease from 15.50 to 13.74 deaths per 1,000 discharges (Beitler et al., 2011). Additionally, results demonstrated a decrease in out-of-ICU mortality from 7.08 to 4.61 deaths per 1,000 discharges and out-of-ICU cardiopulmonary arrest codes from 3.28 to 1.62 codes 1.62 codes per 1,000 discharges after RRT implementation (Beitler et al., 2011). These results can be attributed to the high utilization of RRT with a total of 855 activations for 740 inpatients (Beitler et al., 2011). Beitler, et al. (2011) identified that staff activated RRTs for reasons other than vital sign derangements $43 \%$ of the time including the staff being worried that the patient does not look right (400 activations) and change in mental status 
(368 activations). Establishing a low threshold for RRT activation as well as empowering nurses to use clinical judgment may have direct correlation to the significant reductions in hospital mortality demonstrated in this study. Clinical judgment is largely based off of experience and education which could limit generalizability of this study.

Salvatierra et al. (2014) aimed to assess the relationship between implementing a RRT and hospital mortality rates. Salvatierra et al. (2014) performed an observational cohort study in ten acute tertiary hospitals in Washington State from the years 2001-2009. Data was compared between pre-RRT and post- RRT implementation while controlling for severity of illness (Salvatierra et al., 2014). A total of 471,062 adult patients were included in the study; 235,718 in the pre-RRT time period and 235,344 patients in the post-RRT time period (Salvatierra et al., 2014). Study results demonstrated improvements in in-hospital mortality post-RRT implementation in six out of the ten hospitals (Salvatierra, et al., 2014). Salvatierra et al. (2014) report that due to an overall decline in hospital mortality throughout the United States, they are unable to identify a strong correlation to RRT implementation and decreased mortality rates in their study.

The six hospitals with improved mortality rates had performed formal and mandatory education on RRT before implementation as well as ongoing education throughout implementation (Salvatierra et al., 2014). Three of the four hospitals that did not have improved mortality rates also did not provide mandatory, formal education at the onset of implementation of RRT (Salvatierra et al., 2014). Characteristics of the RRT varied throughout the hospitals with five being a nurse-led team and the others physicianled. Additionally, there was great variability amongst institutions in regards to the number of RRT calls per 1,000 discharges. Salvatierra et al. (2014) are unsure of the 
reason for variations but have been related to underutilization, lack of administration support and infrequent assessment of patients during night shift in prior studies. The number of RRT calls per 1,000 discharges varied from 10 to 325 in hospitals where the RRT was nurse-led and averaged at 2 calls per 1,000 discharges in physician-led RRTs (Salvatierra et al., 2014). A significant limitation to this study is related to the lack of consistency regarding education pre-implementation of RRT as well as RRT composition and characteristics.

Jung et al. (2016) performed a retrospective study to assess the impact of an intensivist-led RRT on mortality in hospitalized patients. Their goal was to implement the RRT in one hospital and compare unexpected mortality rate and incidence of cardiac arrest to data from three control hospitals. The study took place from July 2010 to December 2013 and included a total of 161,071 patients: 68,086 pre-RRT and 69,165 during the RRT period. Prior to the study, codes and triage calls were activated by a traditional pyramid set up; the bedside nurse notified the resident on-call who notified the fellow eventually escalating to the attending to notify the ICU. The pilot hospital received training and education through posters, bedside simulation involving mannequins, practical education sessions and information in the hospital newspaper (Jung et al., 2016). The RRT consisted of an ICU resident, an ICU fellow or attending, and potentially an ICU nurse and could be activated by any caregiver using a dedicated phone number (Jung et al., 2016).

The researchers adjusted for patient's severity amongst hospitals based on the case-mix index and used R software to perform statistical analysis (Jung et al., 2016). Results demonstrated a decrease in unexpected mortality between the pre-RRT and post- 
RRT periods indicating a decrease from 21.9 per 1000 discharges to 17.4 per 1000 discharges (Jung et al., 2016). The three control hospitals did not experience a change in mortality rates (Jung et al., 2016). Additionally, the unexpected hospital mortality following sepsis decreased after the initiation of a RRT, from $4.2 \%$ to $3.1 \%$ (Jung et al., 2016). There was also a decrease in overall mortality in the RRT hospital from 39.6 to 34.6 per 1000 discharges with no significant changes in the control hospitals (Jung et al., 2016). An insignificant decrease in cardiac arrest rates was observed in the RRT hospital from 2.6 to 1.8 per 1000 admissions with no change in cardiac arrests in the control (Jung et al., 2016). A total of 564 RRT were initiated during the 18-month intervention period where the main activation criteria was hypoxemia or a SpO2 $<90 \%$ (Jung et al., 2016). Additionally, patients were more likely to be transferred to the ICU in the RRT hospital (45.8 vs 52.9 per 1000 discharges) compared to the three control hospitals where rates of ICU admission were unchanged (Jung et al., 2016). Patients that were admitted to the ICU during the RRT period were found to have lower Sequential Organ Failure Assessment (SOFA) scores compared to the pre-RRT period (Jung et al., 2016). The researchers identified that there was no significant change in the Simplified Acute Physiology Score II (SAPS II), a mortality estimation tool, as well as ICU mortality, ICU length of stay and mechanical ventilation duration (Jung et al., 2016). Jung et al. (2016) were able to demonstrate a decrease in unexpected and overall morality of hospitalized patients in their study while achieving a high dose of RRT delivery; 29.6 per 1,000 patients, above the recommendation of 25 per 1000 patients. 


\section{Rapid Response Teams and Unplanned Transfers to the ICU}

After implementing the RRT program in 2005 at a 545-bed hospital, Hatlem et al. (2011) were surprised to see a low amount of RRT calls. In order to improve the process and encourage utilization of the RRT, Hatlem et al. (2011) attempted to address barriers and concerns. Doing so allowed for the identification of the problem that staff nurses felt uncomfortable consulting with a team that was physician led and preferred a nurse for peer-to-peer consult (Hatlem et al., 2011). In January 2008, the hospital changed the structure of the RRT by removing the Hospitalist from the team and creating a critical care nurse that performed rounds $24 / 7$. The utilization of a rounding $\mathrm{RN}$ gave staff the option to consult them independently or call the full RRT (Hatlem et al., 2011).

To assess outcomes of the increased call volume experienced after the change in RRT practice, Hatlem et al. (2011) utilized the All Patient Refined Diagnostic-Related Groups (APR DRG) classification system and the Hospital-Standardized Mortality Rate (HSMR). The APR DRG system stratifies a patient's condition into severity of illness (SOI) and risk of mortality (ROM) by utilizing comorbidities. Patients are then assigned an appropriate classification from 1-4, with 4 being significantly higher risk (Hatlem et al., 2011). The HSMR is able to calculate a comparison of the hospital's actual number of deaths with the expected number of deaths based off of national benchmarks (Hatlem et al., 2011).

The results of the study by Hatlem et al. (2011) identified an increase in the number of calls per month from 16 in 2006 to an average of 112 per month in 2008 . The increased RRT usage had a positive impact on the amount of unplanned transfers to the 
ICU with a $35.9 \%$ decrease from 2005 to 2008 (Hatlem et al., 2011). This decrease in unplanned transfers allowed the ICU to have more availability for patients with increased SOI demonstrated by a $12.5 \%$ increase in patients among ROM groups 3 and 4 and a decrease in ROM 1 and 2 (Hatlem et al., 2011). This demonstrates better utilization of resources and improved access to care for more severely ill patients. The last outcome that Hatlem et al. (2011) evaluated was mortality rate. Results demonstrated a 31.2\% reduction in HSMR from 2005 to 2008 but a minimal reduction in overall mortality rate from $2.27 \%$ to $2.21 \%$ (Hatlem et al., 2011). Hatlem et al. (2011) address that overall mortality does not account for patient SOI like the HSMR does. Thus, HSMR is a better indicator of mortality changes as it also focuses on actual deaths rather than expected deaths (Hatlem et al., 2011). This study demonstrates the benefits of assessing staff concerns and recommendations for process improvements to further improve patient outcomes.

The purpose of the study by Kurita et al. (2019) was to assess if hospital volume and RRS call rates had an impact on unplanned ICU admissions. Kurita et al. (2019) performed a retrospective chart analysis of an existing dataset in Japan called the InHospital Emergency Registry (IHER-J). This registry contains data of all RRSs and is maintained by the Japanese Society of Intensive Care Medicine and the Japanese Society for Emergency Medicine (Kurita et al., 2019). After exclusion criteria, 24 hospitals were included in the analysis and 4818 patients (Kurita et al., 2019).

Multivariate analysis was used to assess the association between hospital volume and RRS call rate with unplanned ICU admission (Kurita et al., 2019). Results demonstrated no correlation between the number of hospital beds and amount of RRS 
calls (Kurita et al., 2019). In assessing clinical outcomes, there was an association between hospital volume and increased cardiac arrest on arrival of the RRS team as well as an increased 1-month mortality rate (Kurita et al., 2019). Additionally, RRS call rate was directly related to an increased incidence of cardiac arrest on arrival of the RRS team as well as unplanned ICU admissions (Kurita et al., 2019). In the primary analysis, there was a significant association between a higher RRS call rate and decreased unplanned ICU admissions but not between hospital volume and unplanned ICU admissions (Kurita et al., 2019). Lastly, Kurita et al. (2019) found no significant relationship between the RRS call rate and incidence of cardiac arrest. The direct relationship of higher RRS call relates and decreased unplanned ICU admissions may be related to the ability to provide earlier interventions on a wider range of patients to prevent transfer to the ICU (Kurita et al., 2019).

Next, the theoretical framework will be presented. 


\section{Theoretical Framework}

As a means of evaluating the quality of health care delivery, Avedis Donabedian, physician and researcher, developed the Donabedian model in 1966. Defining quality in terms of medical care is a difficult task as it is frequently "a reflection of values and goals current in the medical care system" (Donabedian, 2005, p. 692). In order to better assess quality of health care, three intertwining dimensions were identified by Donabedian; structure, process and outcome (Figure 1).

Indicators of quality medical care outcomes have been measured in terms of recovery, restoration of function, and survival (Donabedian, 2005). Donabedian (2005) addresses limitations to using outcomes as a means of measuring quality of care including the utilization of survival as a criterion for success. Measures of survival are often used as a quality indicator without taking into consideration the undesired prolongation of life. Although there are limitations to using outcomes as a means of assessing quality, they can still be utilized but with discrimination as outcomes continue to be one of the leading validators of medical care.

In addition to assessing outcomes, Donabedian (2005) emphasizes the importance of examining the process of care. In other words, process includes the method of delivering complete, appropriate care. This includes practitioner judgment, thoroughness of assessment and diagnostics, competence in delivering care including preventive management and ensuring continuity of care (Donabedian, 2005). Lastly, the third approach to assessing quality care in addition to outcomes and process is also taking into consideration the structure. This encompasses the setting of where healthcare is delivered including the availability of facilities and equipment utilized, competencies of staff 
providing care, the organization of administration and management and financial organization (Donabedian, 2005).

There have been several studies that have utilized the Donabedian model of structure, process, and outcome as a framework for research. Notably, Stolldorf (2008) utilized Donabedian's model as guide to evaluate how the implementation of RRTs as a quality improvement initiative would impact the structure, process and outcomes of the United States health care system. Stolldorf (2008) reported that the implementation of RRTs would be a new delivery or process of care that would require changes to the structure of how care is delivered which in turn would affect outcomes of care. The Donabedian model was successfully utilized as a framework for organizing Stolldorf's literature review where they described the U.S. health care system as structure, detailing the development and implementation of RRTs by the Institute for Healthcare Improvement and The Joint Commission. The process of RRTs was further discussed in regards to team composition and calling criteria. Lastly, the outcome component was used to guide the effectiveness of RRTs on cardiopulmonary arrests, inpatient hospital mortality and unplanned ICU admissions.

The utilization of Donabedian's model is only effective when assessing structure, process and outcome as a whole, as each part is dependent on the other. Designed to be a flexible model, these three dimensions can be applied across various healthcare settings. Although the model can be applied to different scenarios, the main theme is as follows; the structure is the healthcare setting, the process is the delivery of care and outcomes are the effects of the quality of healthcare on the patient. This model can be applied to the utilization of Rapid Response Teams in the inpatient setting in that; the structure applies 
to the hospital in which care is provided, the process is the appropriate utilization of RRTs and the clinical decision making abilities of the team, and the outcome is the impact of RRTs interventions on health status of patients including unplanned transfers to the ICU.

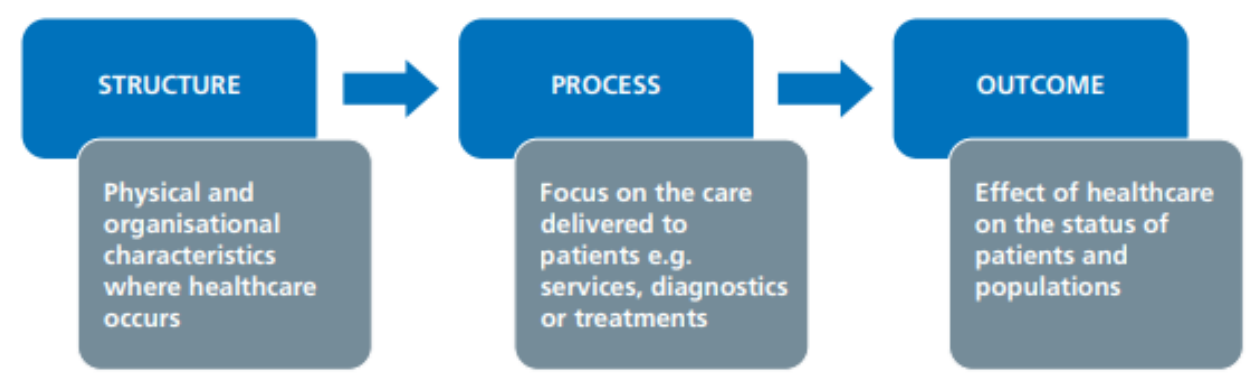

Figure 1. The Donabedian model for quality of care (ACT Academy, 2018).

To enhance the development of this study the Preferred Reporting Items for Systematic Reviews and Meta-Analysis (PRISMA) framework was also utilized in addition to the Donabedian model for quality of care. PRISMA was developed to assist researchers with reporting on or generating a systematic review and meta-analysis that is transparent, accurate and reliable (Moher et al., 2009). Two tools are provided to the researcher for analyzing data: a 27-item checklist (Figure 2) and a four-phase flow diagram (Figure 3) (Moher et al., 2009). According to Moher et al. (2009), the checklist contains items that have been considered essential for transparent reporting of a systematic review. The flow diagram includes four categories that guides the researcher through the phases of performing a systematic review: identification, screening, eligibility, and included (Moher et al., 2009). 


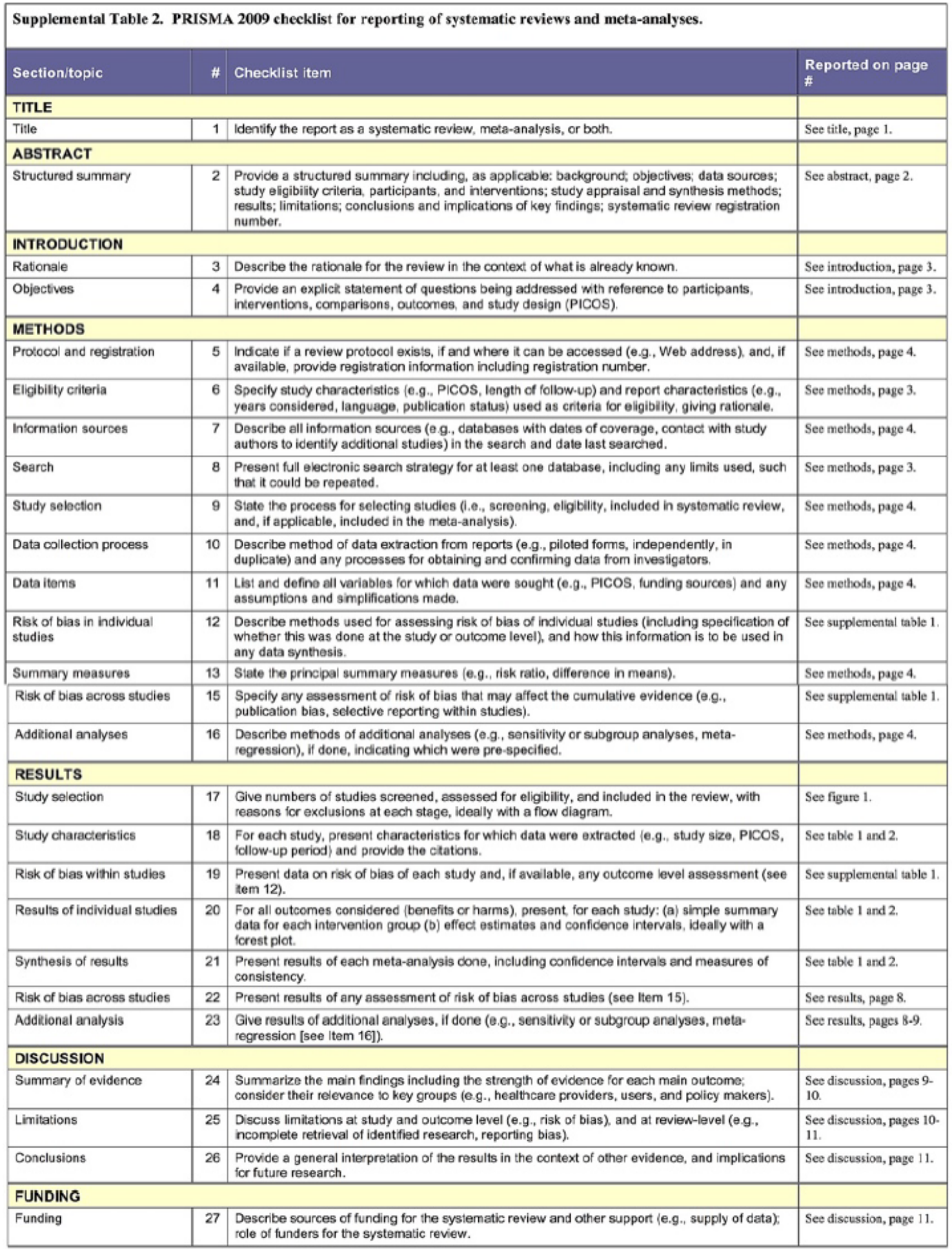

Figure 2. PRISMA Checklist 


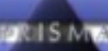

PRISMA 2009 Flow Diagram
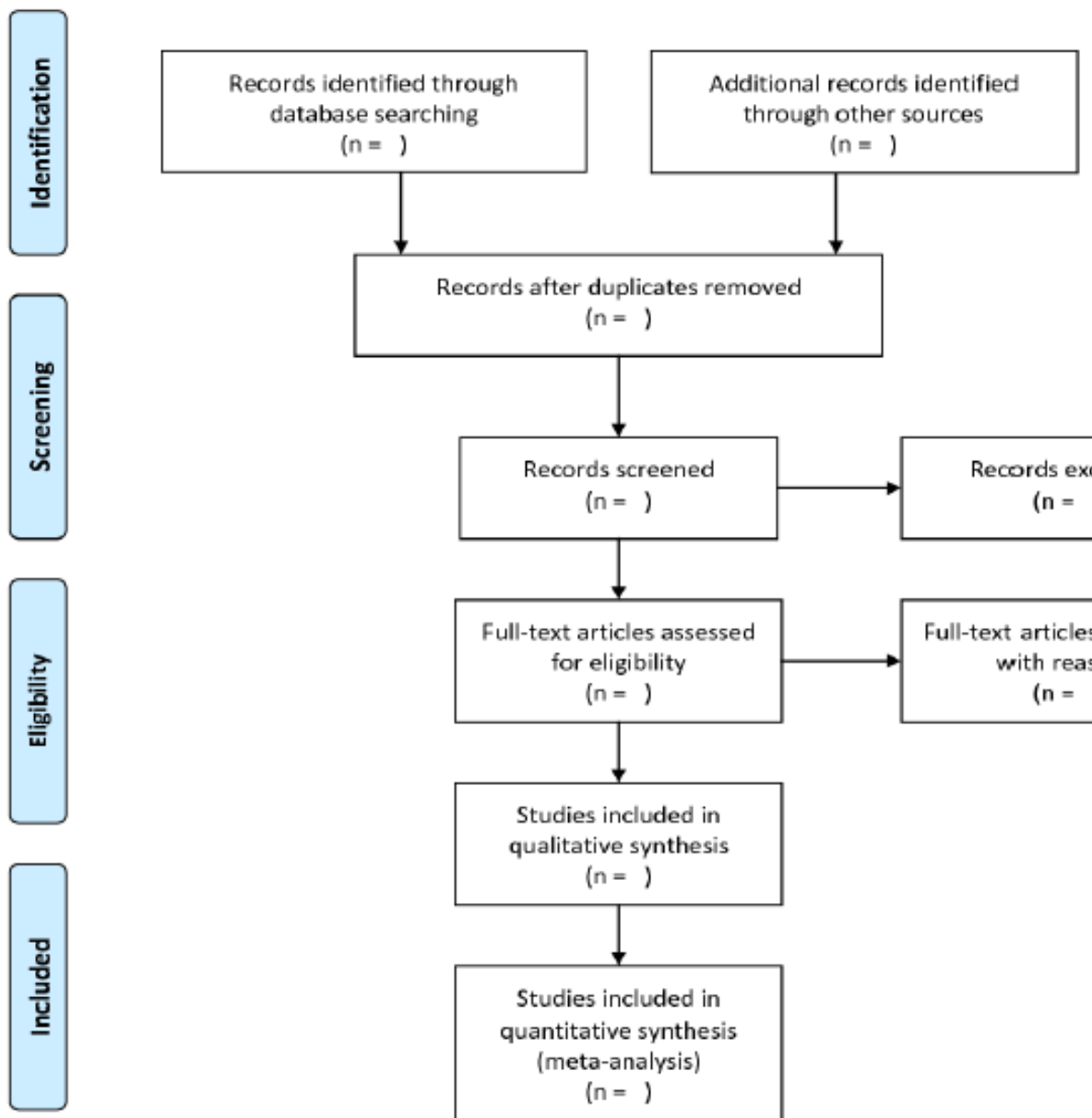

Records after duplicates removed $(\mathrm{n}=)$

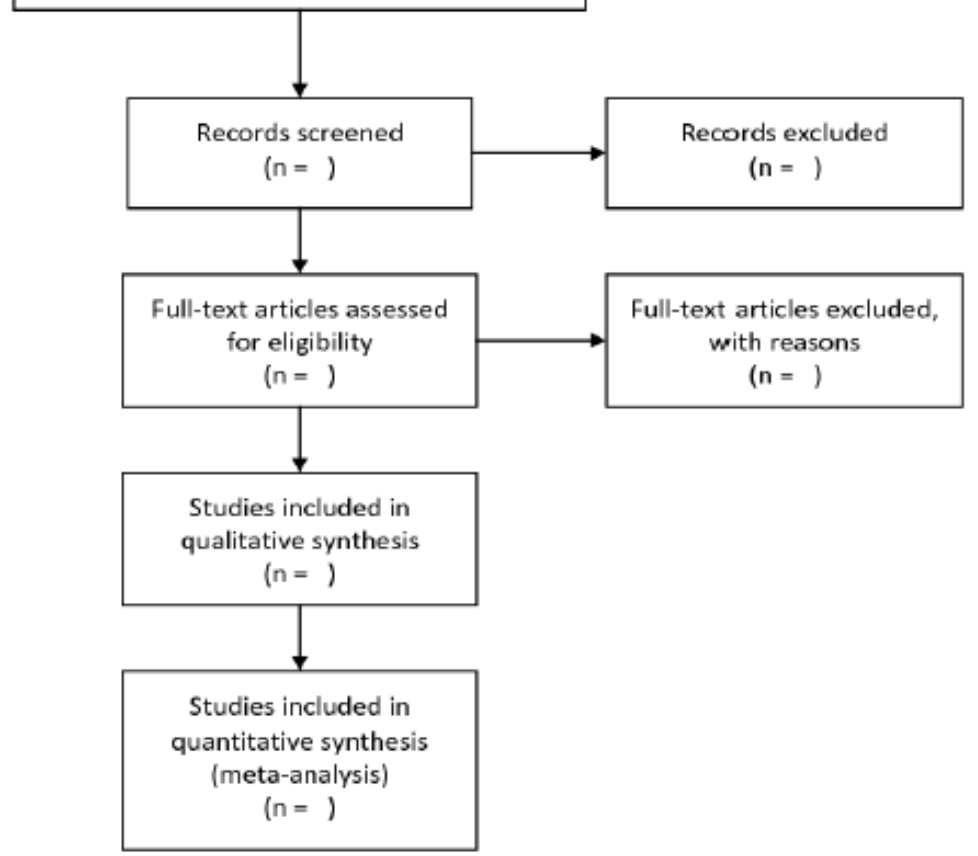

From: Moher D, Liberati A, Tetzlaff J, Altman DG, The PRISMA Group (2009). Prelerred fieporting hems for Systematic Reviews and MetaAnalyses: The PRISMA Statement. PLoS Med 6(6): e1000097. doi:10.1371/journal pmed1000097

For more information, visit www.prisma-statement.org.

\section{Figure 3. PRISMA Flow Diagram}

Next, the methods will be presented. 


\section{Method}

\section{Purpose}

The purpose of this study was to examine the impact and outcomes of Rapid Response Teams on unplanned transfers to the Intensive Care Unit. A systematic review of cohort studies was performed in order to further analyze the topic. Given the nature of the study, human subjects did not participate thus approval from the Institutional Review Board (IRB) was not warranted.

\section{Inclusion/Exclusion Criteria}

Inclusion criteria for the studies included: (a) primary research published from 2010-2020, (b) adult (18 years of age and older) general ward patients, (c) admitted patients that experienced a RRT with unplanned ICU admission following, (d) studies that focused on the analysis of outcomes of patients admitted to the ICU from the wards after RRT, (e) studies that reported quantitative measures of outcomes.

Exclusion criteria for the studies included: (a) studies that were not original research (editorial, letter), (b) studies greater than 10 years old (no later than 2010), (c) included nonadult patients under the age of 18, (d) included adult patients not treated inpatient (emergency department, outpatient), (e) studies that did not have a developed RRT, (f) studies that evaluated multiple outcomes and not solely patients admitted to the ICU. 


\section{Search Strategy}

A detailed search of the PubMed database was conducted on March 8, 2016 to identify relevant literature. The search was implemented using the keywords "RRT" AND "unplanned ICU transfers" as well as "RR” AND "unplanned ICU transfers". Articles were also obtained by viewing "similar articles" on the PubMed database and by performing a manual search of references of included studies. Restrictions included English language and publication year no later than 2010. The four-phase PRISMA flow diagram was utilized to identify, screen, and assess for eligible studies (Moher et al., 2009).

\section{Data Collection}

The student researcher created two data collection tables to organize information from the included studies: study specific data (Appendix A) and outcome data collection (Appendix B). Data extracted from individual studies for study specific data included: study purpose, design, site, sample number, methods, procedures and outcomes. The outcomes that were collected included: number of patients admitted to the ICU after RRT, Acute Physiology and Chronic Health Evaluation (APACHE) II and III scores, ICU and hospital length of stay, ICU and hospital mortality rate, and their statistical significance or $p$-value.

\section{Critical Appraisal}

Critical appraisal of the literature was performed utilizing the Critical Appraisal Skills Programme (CASP) cohort study checklist (Appendix C). CASP provides the student researcher with the tools they need to assess published papers for trustworthiness 
and relevance while also considering strengths and limitations (Critical Appraisal Skills Programme [CASP], 2018). The checklist for cohort studies breaks the appraisal down into twelve questions with three main sections: are the results of the study valid, what are the results, and will the results help locally (CASP, 2018). The CASP for cohort studies was performed on all studies that met inclusion criteria.

\section{Data Synthesis \& Cross Study Analysis}

After critically appraising the identified studies, data synthesis and cross study analysis were completed (Appendix D). The cross-study analysis identified the protocols of the included studies while comparing the following outcomes: patients admitted to the ICU (n), APACHE scores, length of stay (days), and mortality (\%).

Next, the results will be presented. 


\section{Results}

\section{PRISMA 2009 Flow Diagram}

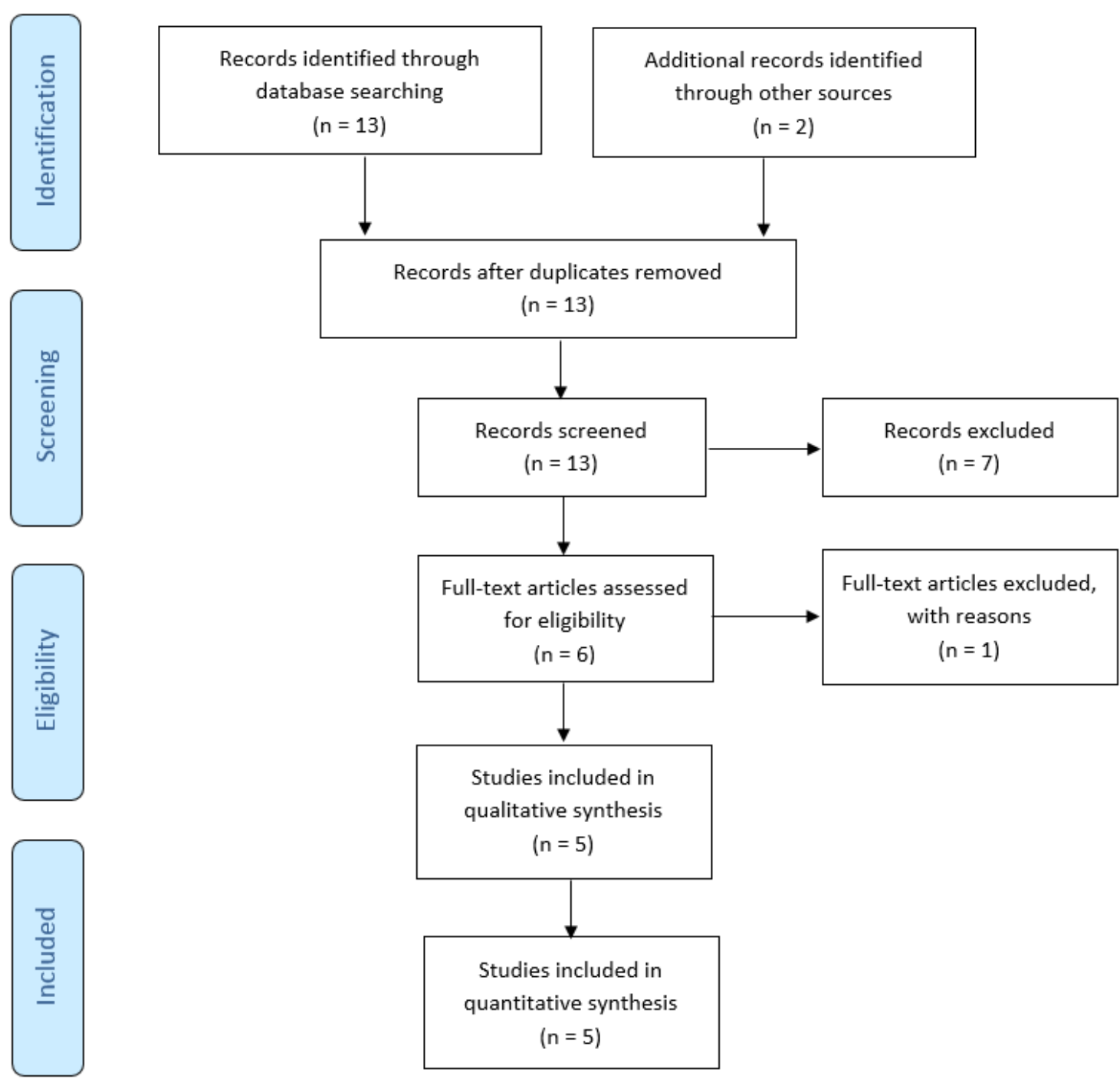

Figure 4. Completed PRISMA flow diagram demonstrating article identification, screening, eligibility, and inclusion (Moher et al., 2009). 
The completed PRISMA flow diagram as shown in Figure 4 demonstrates the identification and screening process for choosing the final five articles for this systematic review. A search with the keywords "RRT" AND "unplanned ICU transfers" as well as "RR” AND “unplanned ICU transfers" resulted in thirteen articles. Additional articles were also obtained by viewing "similar articles" on the PubMed database and by performing a manual search of references of included articles which results in two additional articles. After duplications were removed, a total of thirteen articles were screened. Following article screening, six full-text articles were further assessed for eligibility with one article being excluded. This article was excluded as it did not provide substantial data results for analysis as well as lacked pre-RRT data for comparison of intervention outcomes. At the completion of the four-phase PRISMA flow diagram, a total of five eligible articles were evaluated and selected to complete the systematic review in assessing the impact of RRT activation on unplanned transfers to the ICU.

\section{Individual Studies}

The prospective cohort pre- and post-rapid response team (RRT) implementation study by Al-Omari et al. (2019) (Appendix A, Table A-1) aimed to assess the effectiveness of RRT implementation on patient outcomes. These outcomes included the impact on mortality rate, cardiopulmonary arrests and number of ICU admissions. In the pre-RRT study period, conducted over 36-months (January 2010-Demcember 2012), data was retrieved on a total of 154,869 patients. This data was then compared to a post-RRT study period, 30-month (January 2014-June 2016) population of 466,161 patients. AlOmari et al. (2019) performed their study in four private tertiary hospitals in Saudi Arabia. The researchers retrieved their data from the hospital information system, records 
of the cardiopulmonary resuscitation committee and from the ICU and RRT databases. The outcomes that Al-Omari et al. (2019) aimed to assess were: total hospital admission, total ICU admission, average ICU occupancy rate, total hospital mortality, and total ICU mortality. These outcomes were compared between the pre-RRT and post-RRT study periods. Additional data variables that were analyzed included: patient demographics, RRT activation personnel (doctor vs nurse), RRT triggers, RRT interventions and mortality (patient died in ICU vs ward).

Outcomes of the study by Al-Omari et al. (2019) (Appendix B, Table B-1) demonstrated a decrease in ICU admissions post-RRT compared to pre-RRT. In the postRRT study period there were 1,603 RRT calls and 1,103 (68.81\%) of these patients were admitted to the ICU. When considered per 1000 hospital admissions, there was a decrease from 44.65 pre-RRT to 20.70 post-RRT $(p<0.0001)$. Admission to the ICU post-RRT was related to respiratory causes in $513(46.5 \%)$ of patients. Over half of the patients admitted to the ICU after a RRT call were male gender $(53.52 \%)$. In regards to measuring ICU and hospital length of stay (LOS), Al-Omari et al. (2019) did not provide data from pre-RRT for comparison post-RRT. The ICU LOS for post-RRT patients was 8.7 days with a hospital LOS of 28.8 days. The overall ICU mortality for patients postRRT was 19.58\%; pre-RRT data was not recorded for comparison. Lastly, Al-Omari et al. (2019) did note a decrease in hospital mortality post-RRT compared to pre-RRT; 2.8 per 1000 hospital admissions versus 7.89 per 1000 hospital admissions $(p<0.0001)$.

When critically appraising the integrity of the study utilizing the CASP tool (Appendix C, Table C-1), it was found that the study addressed a clearly focused issue. The pre-post implementation study by Al-Omari et al. (2019) demonstrates a cohort 
representative of a defined population. There does not appear to be selection bias although one cannot accurately interpret this from the study discussion. Objective measurements were utilized in the evaluation of study data and statistical analysis were performed using the SAS software. Additionally, Al-Omari et al. (2019) used the Student $t$ test and chi-square test to compare pre- and post-RRT data and reported relative risk (RR) and 95\% confidence intervals (CIs) for categorial outcomes. A $p$ value of less than or equal to 0.05 was considered to be statistically significant. Although this study demonstrated a large sample size, it is unclear if the results of this study can be applied to the local population given that the study was performed in four private tertiary hospitals. There are also institution specific variables that may impact the generalizability of the results including: maturity of RRT, process of RRT activation and calling criteria, roles of the RRT and RRT composition including who leads the team and quality improvement factors including the monitoring of RRT activations and outcomes. Additional limitations to this study include the evaluation of adult patients, thus excluding the pediatric population and the lack of pre-RRT data for comparison including reason for ICU admission, gender, length of stay and ICU mortality. It would be beneficial to perform multisite, cluster-randomized controlled trial design studies to evaluate the impact RRTs have on patient and hospital outcomes to reduce bias and enhance generalizability. Overall, the study by Al-Omari et al. (2019) showed that RRTs reduced hospital mortality rate and number of unplanned ICU transfers.

The observational prospective study by Jäderling et al. (2013) (Appendix A, Table A-2) aimed to compare characteristics and outcomes of patients admitted to the ICU via RRT versus conventional contact. A total of 694 ICU admissions from general 
wards over a two-year period (2007-2009) were included in the sample size at a university hospital in Stockholm, Sweden. Jäderling et al. (2013) performed their data extraction via the ICU patient database management system, RRT call charts and patient charts. Additionally, in order to assess comorbidities, the Swedish National Inpatient Register and the Cause of Death Register which are run by the National Board of Health and Welfare were utilized. Specific data points that were extracted by the researchers included: ICU admission diagnosis, Acute Physiology and Chronic Health Evaluation (APACHE) II score, date and time for admission and discharge, source of admission, patient demographics, time on non-invasive ventilation (NIIV) or invasive mechanical ventilation (IMV), time on continuous renal replacement therapy (CRRT), documentation of limitations of medical treatment (LOMT), and patient comorbidities.

Outcomes of the study by Jäderling et al. (2013) (Appendix B, Table B-2) shows a slightly higher number of admissions to the ICU after RRT (355) when compared to conventional ICU admission (339). The majority of patients admitted to the ICU after RRT were for reasons related to severe sepsis (65\%) compared to conventional ICU admissions that were admitted for respiratory failure (28\%). The data presented by Jäderling et al. (2013) demonstrates that patients admitted to the ICU after RRT were on average older (65 vs 58$)(p<0.01)$ and male $(62 \%$ vs $50.4 \%)(p<0.01)$. Additionally, the RRT patient population had a longer median ICU LOS ( 2.0 vs 1.2 days) $(p<0.01)$, longer median hospital LOS (18 vs 12.5 days) ( $p<0.01$ ), and higher ICU mortality rate ( $46 \%$ vs 29\%) ( $p$ 0.04). However, the researchers note that after adjusting for age and comorbidities, there was not a significant difference between ICU mortality amongst both 
groups with an odds ratio of 1.11 and a 95\% confidence interval of $0.70-1.76$ (Jäderling et al., 2013).

When critically appraising the integrity of the study utilizing the CASP tool (Appendix C, Table C-2), it was found that the study addressed a clearly focused issue. The observational prospective study by Jäderling et al. (2013) demonstrates a cohort representative of a defined population. The study sample was obtained from a patient database where patients are automatically labeled by how they are admitted to the ICU; ICU vs ICU-RRT. Additional data was obtained from the RRT call charts to validate whether the patient had a RRT call initiated or not. Given the process for data collection reported by Jäderling et al. (2013), there does not appear to be selection bias. Objective measurements were utilized in the evaluation of study data and statistical analysis was performed using STATA/SE 10.1 software. Jäderling et al. (2013) reported continuous data as medians with interquartile ranges (IQRs) and compared using nonparametric test. Although this study was a single-centre design, it occurred in a general ICU of a university hospital which can be applied to local populations. Though, due to the nature of RRT and inter-hospital variations and strategies, it is difficult to determine applicability to other hospitals. Limitations are that it focused solely on adult patients, occurred in one hospital and the maturity of the RRT was not discussed. Jäderling et al. (2013) report an additional limitation is that information about the frequency and timing of vital signs was not obtained on patients prior to RRT activation, thus the potential for delays in activation cannot be measured. In addition to variations in RRT composition and activation criteria, it is also important to consider how well RRT protocol is followed to evaluate whether improvements can be made which was also not reported in this study. 
Jäderling et al. (2013) concluded that RRTs play an important role in detecting complex, vulnerable patients often with severe sepsis, higher severity scores and crude mortality necessitating ICU level of care.

The multicenter, binational, retrospective cohort study performed by Orosz et al. (2020) (Appendix A, Table A-3) aimed to compare characteristics and outcomes of patients admitted to the ICU after RRT versus non-RRT related admissions. Orosz et al. (2020) performed their study in 178 ICUs throughout Australia and New Zealand with a sample size of 97,181 patients. Data was obtained from the Australian and New Zealand Intensive Care Society Adult Patient Database (ANZICS-APD) from 2012-2017. The data extracted by Orosz et al. (2020) included: age, gender, comorbidities, physiologic and laboratory variables to calculate APACHE III scores, the presence of sepsis or infection as an ICU admission diagnosis, date and time of ICU admissions, presence of LOMT, ICU and hospital LOS, survival status, and disposition at the time of hospital discharge.

Outcomes of the study by Orosz et al. (2020) (Appendix B, Table B-3) shows more patients were admitted to the ICU after RRT review (56.7\%) compared to those admitted with no RRT review (43.3\%). There was a higher number of patients admitted to the ICU after RRT review with an infective diagnosis compared to patients with no RRT review ( $32.3 \%$ vs $23.9 \%, p<0.0001)$. The population of patients admitted to the ICU after a RRT were on average 65.4 years old and 53.4\% male $(p<0.0001)$. Orosz et al. (2020) identified in their data that patients admitted to the ICU after a RRT had a higher average APACHE III score (64.6 vs 54.7) $(p<0.0001)$ as well as longer ICU LOS (2.4 days vs 2.1 days), hospital LOS (12.8 days vs 10.8 days), higher ICU mortality (12.3 
vs $7.5 \%)$ and higher hospital mortality ( $20.8 \%$ vs $13.5 \%)$. These results indicate that patients with an underlying infectious diagnosis, more chronic comorbidities and a higher APACHE III score were identified by the RRT and required transfer to the ICU.

When critically appraising the integrity of the study utilizing the CASP tool (Appendix C, Table C-3), it was found that the study addressed a clearly focused issue. multicenter, binational, retrospective cohort study performed by Orosz et al. (2020) demonstrates a cohort representative of a defined population. There does not appear to be selection as all patients were objectively obtained from a binational database, ANZICSAPD. Orosz et al. (2020) quantified data on patient severity of illness by the Australian and New Zealand Risk of Death (ANZROD) measurement, a customized version of the APACHE III for Australia and New Zealand. Objective measurements were utilized in the evaluation of study data and statistical analysis was performed using SAS software. Additionally, Orosz et al. (2020) used the student $t$ test, chi-square test and Wilcoxon rank-sum tests to analyze data. A two-sided $p$ value of 0.01 was considered to be statically significant. The research performed by Orosz et al. (2020) demonstrates potential for generalizability due to the large sample size in 178 ICUs over a six-year period where RRTs are known to be mature. True generalizability is difficult to determine due to the nature of RRT and inter-hospital variations and strategies. As stated by Orosz et al. (2020), limitations of the study include that it is a retrospective design that focused on the adult population and data recorded on patient vital signs in the database may not have been specific to the time during the RRT and may not accurately reflect the RRT events. Another limitation is the structure of RRTs amongst different hospitals including activation criteria and interventions performed during RRT. It is also important 
to note the inability to gather complete data regarding events prior to RRT including if there was a delay in identification of deterioration and intervention or if there were issues with ICU bed availability. Orosz et al. (2020) found that patients with unplanned admissions to the ICU after RRT were more chronically and acutely ill, often presenting with sepsis.

The retrospective before and after cohort study by Karpman et al. (2013) (Appendix A, Table A-4) aimed to assess the impact of RRT implementation on outcomes of patients transferred to the ICU from regular hospital ward and non-ward locations. Karpman et al. (2013) performed their study in two ICUs (one medical, one surgical) of a tertiary medical center in Rochester, Minnesota. The sample population included 4,890 patients admitted to the one of the two ICUs from the ward and 15,855 patients admitted to the ICU from nonward locations. Data was extracted from APACHE III and the administrative hospital and RRT databases. For comparison, the study was divided into two periods; pre-RRT (August 2003-September 2006) and RRT (March 2007-September 2009). Karpman et al. (2013) extracted the following data: ICU type (medical vs surgical), patient demographics, APACHE III comorbidities, APACHE III score and predicted probability of hospital death, use of IMV, ICU admission diagnosis, acute physiology score (APS), ICU and hospital LOS, and ICU and hospital discharge status (dead vs alive).

Outcomes of the study by Karpman et al. (2013) (Appendix B, Table B-4) showed similar results between the pre-RRT period and RRT period with no statistical significance. There were 2,424 (24.1\%) ICU admissions in the RRT period compared to $2,466(23 \%)$ in the pre-RRT period. The primary reason for admission to the ICU was 
respiratory diagnosis (pre-RRT 37.1\%, RRT 37.7\%). The average age of patients was 66.7 years old in the RRT group and 66.0 years old in the pre-RRT group with $44.9 \%$ female and 46.9\% female respectively. Karpman et al. (2013) identified similar median APACHE III scores for the two patient groups (58 RRT, 59 pre-RRT) as well as similar median ICU LOS (3 days) and median hospital LOS (11 days). Lastly, ICU mortality was $10.2 \%$ in the RRT group and $10.5 \%$ in the pre-RRT group with higher hospital mortality rates $(20.9 \%$ vs $19.4 \%$ respectively).

When critically appraising the integrity of the study utilizing the CASP tool (Appendix C, Table C-4), it was found that the study addressed a clearly focused issue. The retrospective before and after cohort study by Karpman et al. (2013) demonstrates a cohort representative of a defined population. There does not appear to be selection bias as all data was obtained from the institutional APACHE III database. Objective measurements were utilized in the evaluation of study data and statistical analysis were performed using PASW Statistics software. Additionally, Karpman et al. (2013) summarized continuous data as a mean SD or median (interquartile range), used the student $t$ test for skewed data, and the chi-square test for compare categorical variables. A $p$ value of less than 0.05 was considered statistically significant. The two study periods were approximately equal in duration with similar sample sizes. Despite the implementation of a RRT, there were marginal differences in outcomes between the two groups. The hospital introduced RRTs in September 2006, the end of the pre-RRT period with hospital wide implementation in March 2007, the start of the RRT period. Thus, the results of this study started from an RRT that had not yet been well established, not leaving room to assess roll-out and make changes before assessing for outcomes. 
Although the RRT study period was over 1.5 years, the beginning data may have skewed data from later in the period where staff may have become more comfortable with appropriate utilization of a RRT. Additionally, despite a relatively long study period with decent sample sizes, it is difficult to determine generalizability of this study due to interhospital variations in RRT and their strategies. A limitation to this is the inability to assess for appropriate utilization of calling criteria by staff, prompt initiation of a RRT at early patient decompensation, roles and composition of the RRT and interventions performed by the team. As stated by Karpman et al. (2013), the daily RRT call rate increased during the last year of the study. Additional limitations of this study are that it was a single-centre retrospective design that studied an adult-only population and that the researchers had limited data to evaluate how the RRT impacted patient outcomes including hospital mortality and cardiac arrest rates. At the completion of the study, Karpman, et al. (2013) concluded that RRTs directly correlated with increased ICU admissions and rates. The researchers also identified that patients with unplanned ICU transfers after RRT were less severely ill but did not have improvements in LOS or mortality.

The retrospective before and after observational study by Joshi et al. (2017) (Appendix A, Table A-5) aimed to evaluate illness severity at ICU admission, ICU LOS and standard RRS outcomes after the implementation of the Queensland-Adult Deterioration Detection System (Q-ADDS)- based RRS. The study occurred at Nambour General Hospital in Nambour, Queensland. The sample size included a total of 420 patients admitted to the ICU from the general wards. For purposes of comparison, Joshi et al. (2017) included a pre-RRS revision period (July 2010 to December 2011) and a 
post-RRS revision period (July 2012-December 2013). For every unplanned ICU admission, the researchers collected data from the Australian and New Zealand Intensive Care Society AORTIC program. Joshi et al. (2017) extracted the following data:

APACHE II and III scores, simplified APS (SAPS) scores on ICU admission, initiation of organ support while in ICU, ICU and hospital LOS, prolonged ICU stays ( $>7$ days), ICU and hospital mortality, and AORTIC data of hospital survival of patients admitted to the ICU. Outcomes identified by Joshi et al. (2017) included severity of illness scores, need for initiation of organ support, ICU and hospital LOS, ICU prolonged stay, ICU and hospital mortality, number of RRS activations, cardiorespiratory arrests, and unplanned ICU admissions.

Outcomes of the study by Joshi et al. (2017) (Appendix B, Table B-5) showed an increase in patients admitted to the ICU after RRS revision (239 patients vs 181 patients). The average age of patients in the post-RRS revision period was 64.3 years old compared to 64.1 years old in the pre-RRS revision. Over half of the patients admitted to the ICU in both groups were male (pre-RRS 53.6\%, post-RRS 56.9\%). Patients admitted to the ICU post-RRS revision demonstrated a lower median APACHE II (17 vs 21 pre-RRS) and APACHE III score (64 vs 68 pre-RRS). Median ICU LOS and hospital LOS were also lower in the post-RRS revision group compared to the pre-RRS revision group (3 vs 4 days and 4.93 vs 5.65 days). Lastly, there was a higher median ICU mortality and hospital mortality amongst patients admitted to the ICU from general wards post-RRS revision ( $13.8 \%$ vs $13.7 \%$ and $20.9 \%$ vs $20.4 \%)$.

When critically appraising the integrity of the study utilizing the CASP tool (Appendix C, Table C-5), it was found that the study addressed a clearly focused issue. 
The retrospective before and after observational study by Joshi et al. (2017) demonstrates a cohort representative of a defined population. There does not appear to be a selection bias as all data was obtained from the Australian and New Zealand Intensive Care Society (AORTIC) program. Objective measurements were utilized in the evaluation of study data and statistical analysis were performed using STATA and MS Excel. Additionally, Joshi et al. (2017) reported data utilizing the mean and median, binary data was expressed as proportions (\%), continuous data was assessed using the Shapiro-Wilk test, non-normally distributed data was analyzed with the Mann-Whitney U-test and normally distributed data were analyzed using the student's t-test. A statistically significant $p$ value was set at $<0.05$. Due to the nature of RRS and inter-hospital variations and strategies, it is difficult to determine applicability of this study to other hospitals. Limitations of this study include the study being a single-centre, retrospective observational design that studied adult patients only. There are also variables that may affect the outcomes of a RRS but aren't able to be directly measured. Variables to consider include the structure and function of the RRT, appropriate utilization of calling criteria, prompt assessment and intervention of patient decompensation, staff education and comfort level of activating the RRT and quality improvement aspects to enhance outcomes.

\section{Cross-Study Analysis}

The cross-study analysis table (Appendix D) identifies the protocols of the included studies while comparing the following outcomes: patients admitted to ICU $(n)$, APACHE score, length of stay (days), and mortality (\%). All studies investigated all of the identified variables except for one; Al-Omari et al. (2019) did not measure APACHE 
scores as an outcome variable. Additionally, the protocols of all the studies involved a comparison of either pre-RRT implementation and post-RRT implementation (study 1, 2, $3,4)$ or pre-RRS revision and post-RRS revision (study 5).

Upon further analysis, it is identified that the studies had varying results with no consistent patterns noted. In regards to number of patients admitted to the ICU, two of the four studies that compared pre and post RRT implementation noted decreased admissions to the ICU (study 1 and 4) while study 2 and 3 identified an increased number of ICU admissions after RRT implementation. Study 5 evaluated outcomes of patients admitted to the ICU after revision of an already established RRT and found an increased number of ICU admissions.

In regards to measuring APACHE scores, study 1 did not include this data in their results. Two of the four studies that measured APACHE scores found patients had higher APACHE II (study 2) and APACHE III (study 3) results. Comparatively, study 4 noted a decreased in APACHE III scores and study 5 noted a decrease in APACHE II and APACHE III. There was also great variability when measuring length of stay as an outcome. Study 1 did not provide pre-RRT data for comparison to evaluate the impact RRT implementation had on ICU and hospital LOS. Additionally, study 4 noted no significant changes in their ICU and hospital LOS after RRT implementation. Studies 2 and 3 both noted an increased ICU and hospital LOS in patients admitted to the ICU after RRT call. Lastly, study 5 noted a reduction in median ICU and hospital LOS. When considering mortality as an outcome there again was variability amongst studies. A higher ICU mortality rate was noted in study 2 and a higher ICU and hospital mortality rate was noted in study 3 and 5. On the other hand, study 4 saw a decrease in ICU 
mortality and an increase in hospital mortality with patients admitted to the ICU after RRT. Lastly, there was a decrease in hospital mortality in study 1 and no pre-RRT data was provided for comparison in regards to ICU mortality.

Next, the summary and conclusions will be presented. 


\section{Summary and Conclusions}

Rapid Response Teams (RRT) are an evolution of the Medical Emergency Team (MET) originally developed in Australia in the 1990s (DeVita et al., 2014). These teams were then acknowledged by the Institute for Healthcare Improvement (IHI) and incorporated into the 2008 National Patient Safety Goals (Revere \& Eldridge, 2008) to address inpatient hospital morbidity and mortality in the United States (Institute for Healthcare Improvement, 2006). The term RRT was coined and is used nationwide in addition to being called Rapid Response Systems (RRS) and MET.

It was recognized that patients present with signs and symptoms of deterioration before an emergency or cardiac arrest occurs. To assist in the recognition of acute changes in clinical status, the MET was created with the goal of bringing advanced skills and interventions to the bedside of the deteriorating patient quickly. There have been numerous studies on what criteria are considered in the activation of RRT or MET. These indications are also referred to as calling criteria and vary greatly amongst different institutions. Overall, the criteria include a change in patient's vital signs, neurological status, cardiac status or a respiratory impairment that warrant prompt intervention. The RRT has been shown to have varying members from various specialties but generally includes a critical care physician, critical care nurse and respiratory therapist.

In assessing the success of RRT, three main outcomes are generally measured: rate of inpatient cardiopulmonary arrests, hospital mortality rate and number of unplanned transfers to the ICU. Rapid response teams were implemented to assist in early detection of patient deterioration to promote early intervention. Ideally, this should decrease inpatient cardiopulmonary arrests, improve hospital mortality and decrease the 
number of unplanned transfers to the ICU. After performing a review of the literature, there have been consistently varying outcome findings in regards to all three identified goals. It was identified that more literature focused on cardiopulmonary arrest and mortality outcomes and less on measuring the impact of RRT on unplanned admissions to the ICU. To better understand this individual outcome, a systematic review was developed to investigate the impact of RRT activation on unplanned transfers to the ICU.

After identifying a need for further evaluation of research regarding this topic, a comprehensive literature review was performing using the PubMed database. This review focused solely on RRTs and unplanned transfers to the ICU and how patient and hospital outcomes are affected. To guide the development of this systematic review, the Donabedian model for quality of care as well as PRISMA were used in the theoretical framework. The Donabedian model was developed as a means of better assessing the quality of healthcare. This model focuses on the value of intertwining three dimensions: structure, process and outcome (Donabedian, 2005). It is noted that these three dimensions are measured as a whole and not independently as the outcome (how patients and populations are affected) of delivering quality care relies on the structure or characteristics of the healthcare setting and the process in which care is delivered (diagnostics, treatments, services) (Donabedian, 2005). The PRISMA framework consists of a 27 -item checklist and a four-phase flow diagram to assist in identifying research that is transparent and reliable (Moher et al., 2009).

Following a thorough literature search, where the final five studies were identified for inclusion, an individual study analysis occurred. This analysis involved data collection and the creation of study specific tables to identify key study information. Data 
outcome tables were developed to assess how RRTs impacted measurable outcomes of patients admitted to the ICU. Critical appraisal was performed of all articles utilizing the CASP checklist. Lastly, a cross study analysis table was developed to compare the impact of RRT on ICU admissions on the number of ICU admissions after RRT review, APACHE scores, ICU and hospital LOS and ICU and hospital mortality.

The implementation of RRT throughout the nation and internationally has grown in an attempt to improve patient and hospital outcomes. However, many researchers have found conflicting results in the impact that RRTs have on these outcomes. Limitations of the identified studies included the study designs, inability to predict generalizability and institution specific variables regarding RRTs. One study did not provide pre-RRT data which prevented a thorough assessment of outcomes after RRT implementation. It is important to note that all of the study designs were observational prospective or retrospective cohort studies. There are also institution specific variables that may impact the generalizability of results including: maturity of RRT, process of RRT activation and calling criteria, roles of the RRT and RRT composition including who leads the team and quality improvement factors including the monitoring of RRT activations and outcomes. One study reported the inability to obtain data about the frequency and timing of vital signs prior to RRT activation and if assessment of patient deterioration was prompt. It was also noted to be difficult to assess whether or not RRT protocol was followed per institution guidelines to evaluate for future improvements in the process.

This systematic review presents conflicting findings with no particular pattern identified. In this review there was noted to be both an increased and decreased number of ICU admissions following RRT implementation. There were also patients that were 
admitted to the ICU with higher and lower APACHE scores following RRT review.

Lastly, RRT implementation varied amongst studies in how it impacted patient LOS and mortality; seeing an increase and a decrease amongst studies.

Next, the recommendations and implications for advanced nursing practice will be presented. 


\section{Recommendations and Implications for Advanced Nursing Practice}

Rapid response teams have the potential to positively affect patient and hospital outcomes. Their success lies heavily on a strong foundation, the collaboration of interdisciplinary team members as well as institution support. This can also be referred to as the structure of the rapid response team as identified in Donabedian's quality of care model. Although the research demonstrates variations in the structure and implementation of RRTs, there are foundational aspects that can be applied for success. The development of a RRT should be guided by the latest research to understand what measures are successful and which need improvement. After creating a strong structure, it is vital to ensure a strong process follows. It is important to properly educate and support staff on the importance of early detection and activation of a RRT. In most institutions, the staff on the afferent limb of a RRT can be anyone at the patient's bedside but focus largely on the RN, MD and sometimes visiting family members of the patient. Prompt assessment of patient deterioration is imperative to early intervention and successful outcomes. Instilling confidence in the activating staff promotes personal and professional growth while encouraging critical thinking skills and enhancing patient outcomes. Implementation of a RRT should include feedback from staff, evaluation, revision and reevaluation of outcomes to make improvements in the process. The development of a RRT algorithm is beneficial in encouraging staff to activate a RRT and serves as a guideline to reference. Assessing the integrity of the efferent limb, responding team, is also essential to a successful RRT. There should be clear identification of the members and roles that the RRT is composed of. This eliminates confusion amongst staff at the bedside who are activating and responding to the RRT and encourages efficiency. Lastly, 
as identified in the Donabedian model of quality of care, the structure and process directly affect the outcome. Quality measures should be identified and tracked to evaluate how the RRT is functioning and where improvements can be made.

Although there were limitations throughout the studies in this systematic review, the results assist in identifying future implications. There is a need for further research to evaluate outcomes of RRT. Studies that evaluate outcomes in large sample sizes and are multicenter, cluster-randomized controlled trial design may provide stronger evidence. It would be beneficial to do more recent research to assess how mature RRT have grown and involved and how their outcomes have changed as compared to when they were first developed. It is also important to continue to encouraged early identification of patient deterioration and develop an efficient method that eliminates variations in practice. There may be technological capabilities with the growing utilization of the electronic medical record to assist staff on the afferent limb in recognizing deterioration.

The evolution of RRTs can be largely supported by the Advance Practiced Registered Nurse (APRN) as they serve as strong members of the healthcare team. The APRN can utilize their experience in clinical care and research to bridge the gap between staff at the bedside, providers and leadership. There is a growing need for APRNs in policy development, education and research roles. Rapid response teams serve as an ideal opportunity for the APRN to showcase their abilities to become involved at varying levels. Whether it be continued research to encourage evidence-based practice, policy and protocol development, or education and training to build confidence in the healthcare team. 


\section{References}

ACT Academy. (2018). A model for measuring quality care. NHS Improvement, 1-4. https://improvement.nhs.uk/documents/2135/measuring-quality-care-model.pdf

Agency for Healthcare Research and Quality. (2019, September 8). Rapid Response Systems. https://psnet.ahrq.gov/primer/rapid-response-systems

Al-Omari, A., Al Mutair, A., \& Aljamaan, F. (2019). Outcomes of rapid response team implementation in tertiary private hospitals: a prospective cohort study. International Journal of Emergency Medicine, 12(31), 1-5. https://doi.org/10.1186/s12245-019-0248-5

Angel, M., Ghneim, M., Song, J., Brocker, J., Tipton, P. H., \& Davis, M. (2016). The Effects of a Rapid Response Team on Decreasing Cardiac Arrest Rates and Improving Outcomes for Cardiac Arrests Outside Critical Care Areas. Med Surg Nursing, 25(3), 153-158. doi: PMID: 27522841

Bagshaw, S. M., Mondor, E. E., Scouten, C., Montgomery, C., Slater-MacLean, L., Jones, D. A., Bellomo, R., \& Noel Gibney, R. T. (2010). A Survey of Nurses’ Beliefs About the Medical Emergency Team System in a Canadian Tertiary Hospital. American Journal of Critical Care, 19(1), 74-83. https://doi.org/10.4037/ajcc2009532

Beitler, J. R., Link, N., Bails, D. B., Hurdle, K., \& Chong, D. H. (2011). Reduction in hospital-wide mortality after implementation of a rapidresponse team: a long-term cohort study. Critical Care, 15(6), R269. https://doi.org/10.1186/cc10547

Chen, J., Bellomo, R., Hillman, K., Flabouris, A., \& Finfer, S. (2010). Triggers for emergency team activation: A multicenter assessment. Journal of Critical Care, 25(2), 359.e1-359.e7. https://doi.org/10.1016/j.jcrc.2009.12.011 
Critical Appraisal Skills Programme. (2018). CASP cohort study checklist. Retrieved from https://casp-uk.b-cdn.net/wp-content/uploads/2018/03/CASP-Cohort-StudyChecklist-2018_fillable_form.pdf

Davis, D. P., Aguilar, S. A., Graham, P. G., Lawrence, B., Sell, R. E., Minokadeh, A., \& Husa, R. D. (2015). A novel configuration of a traditional rapid response team decreases non-intensive care unit arrests and overall hospital mortality. Journal of Hospital Medicine, 10(6), 352-357. https://doi.org/10.1002/jhm.2338

DeVita, M. A., Bellomo, R., Hillman, K., Kellum, J., Rotondi, A., Teres, D., Auerbach, A., Chen, W.J., Duncan, K., Kenward, G., Bell, M., Buist, M., Chen, J., Bion, J., Kirby, A., Lighthall, G., Ovreveit, J., Braithwaite, S., Gosbee, J., Millbrandt, E., ... Galhotra, S. (2006). Findings of the First Consensus Conference on Medical Emergency Teams*. Critical Care Medicine, 34(9), 2463-2478.

https://doi.org/10.1097/01.ccm.0000235743.38172.6e

DeVita, M. A., Hillman, K., \& Smith, G. B. (2014). Resuscitation and rapid response systems. Resuscitation, 85(1), 1-2. https://doi.org/10.1016/j.resuscitation.2013.11.005

Donabedian, A. (2005). Evaluating the quality of medical care. The Milbank Quarterly, 83 (4), 691-729. https://doi.org/10.1111/j.1468-0009.2005.00397.x

Galhotra, S., Devita, M. A., Simmons, R. L., \& Dew, M. A. (2007). Mature rapid response system and potentially avoidable cardiopulmonary arrests in hospital. Quality and Safety in Health Care, 16(4), 260-265. doi:

10.1136/qshc. 2007.022210 
Hall, M. J., Levant, S., \& DeFrances, C. J. (2013). Trends in Inpatient Hospital Deaths: National Hospital Discharge Survey, 2000-2010. NCHS Data Brief, (118), 1-8. Centers for Disease Control and Prevention. https://www.cdc.gov/nchs/data/databriefs/db118.pdf

Hatlem, T., Jones, C., \& Woodard, E. K. (2011). Reducing Mortality and Avoiding Preventable ICU Utilization: Analysis of a Successful Rapid Response Program Using APR DRGs. Journal For Healthcare Quality, 33(5), 7-16. https://doi.org/10.1111/j.1945-1474.2011.00084.x

Institute for Healthcare Improvement (2006). 100,000 Lives Campaign: A scientific and policy review. Joint Commission Journal on Quality and Patient Safety, 32, 621627.

Jackson, S., Penprase, B., \& Grobbel, C. (2016). Factors Influencing Registered Nurses’ Decision to Activate an Adult Rapid Response Team in a Community Hospital. Dimensions of Critical Care Nursing, 35(2), 99-107. https://doi.org/10.1097/dcc.0000000000000162

Jäderling, G., Bell, M., Martling, C.-R., Ekbom, A., Bottai, M., \& Konrad, D. (2013). ICU Admittance by a Rapid Response Team Versus Conventional Admittance, Characteristics, and Outcome*. Critical Care Medicine, 41(3), 725-731. https://doi.org/10.1097/ccm.0b013e3182711b94

Jones, D., Baldwin, I., McIntyre, T., Story, D., Mercer, I., Miglic, A., Goldsmith, D., \& Bellomo, R. (2006). Nurses' attitudes to a medical emergency team service in a teaching hospital. Quality and Safety in Health Care, 15(6), 427-432. https://doi.org/10.1136/qshc.2005.016956 
Jones, D., Drennan, K., Hart, G. K., Bellomo, R., \& Web, S. A. R. (2012). Rapid Response Team composition, resourcing and calling criteria in Australia. Resuscitation, 83, 563-567. doi: 10.1016/j.resuscitation.2011.10.023

Joshi, K., Campbell, V., Landy, M., Anstey, C. M., \& Gooch, R. (2017). The Effect of Rapid Response System Revision on Standard and Specific Intensive Care Unit Outcomes in a Regional Hospital. Anaesthesia and Intensive Care, 45(3), 369374. https://doi.org/10.1177/0310057x1704500313

Jung, B., Daurat, A., De Jong, A., Chanques, G., Mahul, M., Monnin, M., ... Jaber, S. (2016). Rapid response team and hospital mortality in hospitalized patients. Intensive Care Medicine, 42(4), 494-504. https://doi.org/10.1007/s00134-016-4254-2

Karpman, C., Keegan, M. T., Jensen, J. B., Bauer, P. R., Brown, D. R., \& Afessa, B. (2013). The Impact of Rapid Response Team on Outcome of Patients Transferred from the Ward to the ICU. Critical Care Medicine, 41(10), 2284-2291. https://doi.org/10.1097/ccm.0b013e318291cccd

Kurita, T., Nakada, T., Kawaguchi, R., Fujitani, S., Atagi, K., Naito, T., ... Oda, S. (2019). Impact of increased calls to rapid response systems on unplanned ICU admissions: Japanese database study. The American Journal of Emergency Medicine. https://doi.org/10.1016/j.ajem.2019.10.028

Moher, D., Liberarti, A., Tetzlaff, J. Altman, D. G., \& The PRISMA group. (2009). Preferred reporting items for systematic reviews and meta-analyses: The prisma statement. PLoS Medicine, 6(7), 1-6. doi:10.1371/journal.pmed.1000097 
Orosz, J., Bailey, M., Udy, A., Pilcher, D., Bellomo, R., \& Jones, D. (2020). Unplanned ICU Admission From Hospital Wards After Rapid Response Team Review in Australia and New Zealand. Critical Care Medicine, 48(7), e550-e556. https://doi.org/10.1097/ccm.0000000000004353

Padilla, R. M., Urden, L. D., \& Stacy, K. M. (2018). Nurses’ Perceptions of Barriers to Rapid Response System Activation. Dimensions of Critical Care Nursing, 37(5), 259-271. https://doi.org/10.1097/dcc.0000000000000318

Radeschi, G., Urso, F., Campagna, S., Berchialla, P., Borga, S., Mina, A., Penso, R., Di Pietrantonj, C., Sandroni, C. (2015). Factors affecting attitudes and barriers to a medical emergency team among nurses and medical doctors: A multi-centre survey. Resuscitation, 88, 92-98. https://doi.org/10.1016/j.resuscitation.2014.12.027

Raymond, A., Porter, J. E., Missen, K., Larkins, J.-A., Vent, K. de, \& Redpath, S. (2019). The meaning of 'worried' in MET call activations: A regional hospital examination of the clinical indicator. Collegian, 26, 378-382. https://doi.org/10.1016/j.colegn.2018.11.002

Revere, A., \& Eldridge, N. (2008). Joint Commission National Patient Safety Goals for 2008. Topics in Patient Safety, 12(1), 1-4. VA National Center for Patient Safety. https://www.patientsafety.va.gov/docs/TIPS/TIPS_JanFeb08.pdf

Salvatierra, G., Bindler, R. C., Corbett, C., Roll, J., \& Daratha, K. B. (2014). Rapid Response Team Implementation and In-Hospital Mortality*. Critical Care Medicine, 42(9), 2001-2006. https://doi.org/10.1097/ccm.0000000000000347 
Santiano, N., Young, L., Hillman, K., Parr, M., Jayasinghe, S., Baramy, L.-S., ... Hanger, G. (2009). Analysis of Medical Emergency Team calls comparing subjective to “objective" call criteria. Resuscitation, 80(1), 44-49. https://doi.org/10.1016/j.resuscitation.2008.08.010

Stolldorf, D. (2008). Rapid Response Teams: Policy Implications and Recommendations for Future Research. Journal of Nursing Law, 12(3), 115-123. doi: 10.1891/10737472.12 .3 .115

Stolldorf, D. P., \& Jones, C. B. (2015). The Deployment of Rapid Response Teams in U.S. Hospitals. The Joint Commission Journal on Quality and Patient Safety, 41(4). doi: 10.1016/s1553-7250(15)41024-4 
Table A-1

Appendix A

Study Specific Data

Study 1: Al-Omari, A., Al Mutair, A., \& Aljamaan, F. (2019). Outcomes of rapid response team implementation in tertiary private hospitals: a prospective cohort study. International Journal of Emergency Medicine, 12(31), 1-5. https://doi.org/10.1186/s12245-019-0248-5

$\underline{\text { Aim }} \underline{\underline{\text { Design }}} \underline{\underline{\text { Site }} \quad \underline{\text { Sample }} \underline{\text { Method }} \text { Procedure }}$

To evaluate the effectiveness

of the rapid

Prospective

cohort pre- and post-RRT

response team

(RRT)

implementation

implementation

in reducing the

mortality rate,

number of

cardiopulmona

ry arrests, and

number of ICU

admissions.
4 tertiary

Pre-RRT

private

period:

hospitals $\quad 154,869$

Data was obtained from the hospital information system, from the records of the cardiopulmonary resuscitation committee, and from the Arabia patients

Post-RRT period: 466 , 161 patients
Pre- and post-RRT data were assessed and compared. Outcomes included: total hospital admission, total ICU admission, average ICU occupancy rate, total hospital mortality, and total ICU mortality. RRT data reviewed included: demographics, RRT activation personnel (doctor or nurse), RRT triggers, RRT intervention, and mortality.

Statistical analysis using SAS software, the student $t$ test and chi-square test to compare the difference between groups. Relative risk (RR) and $95 \%$ confidence intervals (CIs) were reported for categorical outcomes.

Note: RRT-rapid response team, ICU- intensive care unit, RR-relative risk, CI-confidence interval 
Table A-2

\section{Appendix A}

Study Specific Data

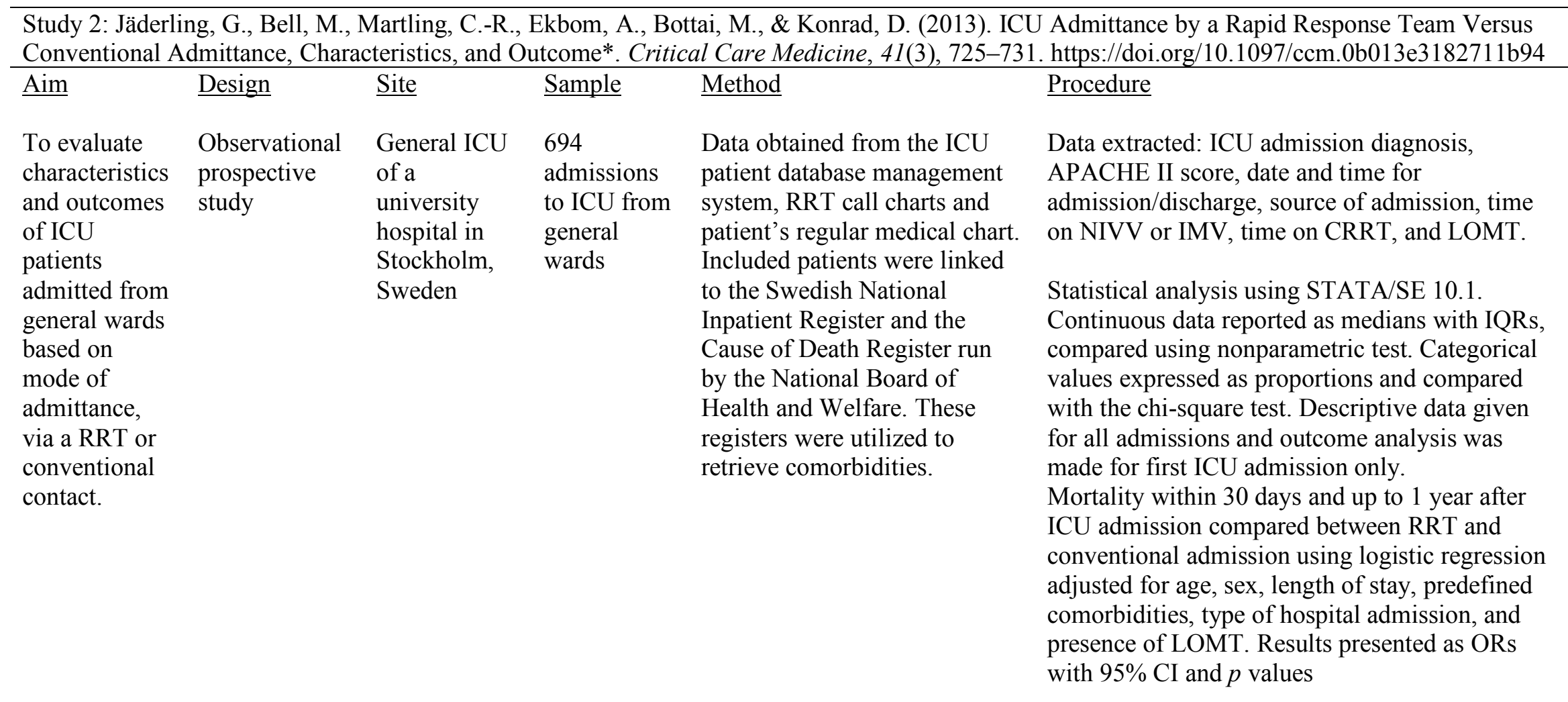

Note: ICU-intensive care unit, APACHE-acute physiology and chronic health evaluation, CRRT-continuous renal replacement therapy, NIVVnoninvasive ventilation, IMV-invasive mechanical ventilation, LOMT-limitations of medical treatment, IQR-interquartile range, OR-odds ratio, CIconfidence interval 
Table A-3

\section{Appendix A}

Study Specific Data

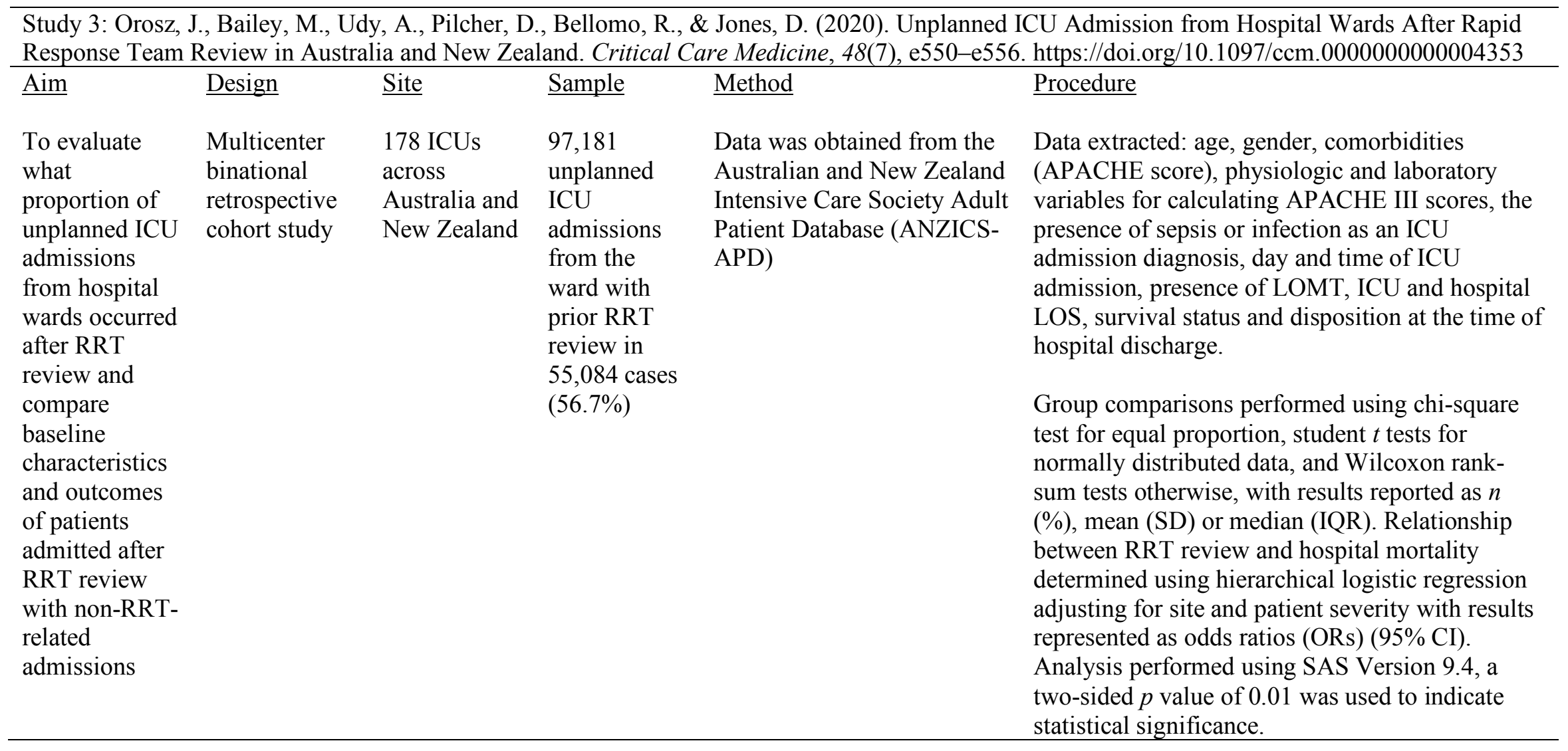

Note: ICU-intensive care unit, RRT-rapid response team, APACHE-acute physiology and chronic health evaluation, LOMT-limitations of medical treatment, LOS-length of stay, SD-standard deviation, IQR-interquartile range 
Table A-4

Appendix A

Study Specific Data

\begin{tabular}{|c|c|c|c|c|c|}
\hline \multicolumn{6}{|c|}{$\begin{array}{l}\text { Study 4: Karpman, C., Keegan, M. T., Jensen, J. } \\
\text { Outcome of Patients Transferred from the Ward } \\
\text { https://doi.org/10.1097/ccm.0b013e318291cccd }\end{array}$} \\
\hline Aim & Design & Site & $\underline{\text { Sample }}$ & Method & Procedure \\
\hline $\begin{array}{l}\text { regular hospital } \\
\text { ward and non- } \\
\text { ward locations } \\
\text { to the ICU }\end{array}$ & & & $\begin{array}{l}\text { patients } \\
\text { admitted } \\
\text { from } \\
\text { nonward } \\
\text { locations }\end{array}$ & & $\begin{array}{l}\text { Continuous data were summarized as a mean } \pm \\
\text { SD or median (IQR) for skewed data. Categorical } \\
\text { data were summarized as percentages. Student } t \\
\text { test or Mann-Whitney } U \text { test for skewed data, was } \\
\text { used to compare continuous data among groups. } \\
\text { Chi-square test was used to compare categorical } \\
\text { variables. Multiple logistic regression model was } \\
\text { developed by entering APACHE III predicted } \\
\text { mortality and RRT period as predictor variables } \\
\text { and hospital mortality as the outcome variable. } \\
\text { For each of the predicted variables, the OR and } \\
\text { 95\% CI were calculated; } p \text { values }<0.05 \text { were } \\
\text { considered statistically significant. All statistical } \\
\text { analyses performed using PASW Statistics } 18 \text { and } \\
\text { MedCalc Software. }\end{array}$ \\
\hline
\end{tabular}

Note: RRT-rapid response team, ICU-intensive care unit, APACHE-acute physiology and chronic health evaluation, IMV-invasive mechanical ventilation, APS-acute physiology score, LOS-length of stay, SD-standard deviation, IQR-interquartile range, OR-odds ratio, CI-confidence interval 
Table A-5

Appendix A

Study Specific Data

\begin{tabular}{lllll}
\hline Study 5: Joshi, K., Campbell, V., Landy, M., Anstey, C. M., \& Gooch, R. (2017). The Effect of Rapid Response System Revision on Standard and \\
Specific Intensive Care Unit Outcomes in a Regional Hospital. Anaesthesia and Intensive Care, 45(3), 369-374. \\
https://doi.org/10.1177/0310057x1704500313
\end{tabular}

Note: RRS-rapid response system, ICU-intensive care unit, LOS-length of stay, APACHE-acute physiology and chronic health evaluation, IMVinvasive mechanical ventilation, APS-acute physiology score, LOS-length of stay, SD-standard deviation, IQR-interquartile range, OR-odds ratio, CI-confidence interval 
Table B-1

\section{Appendix B}

Outcome Data Collection

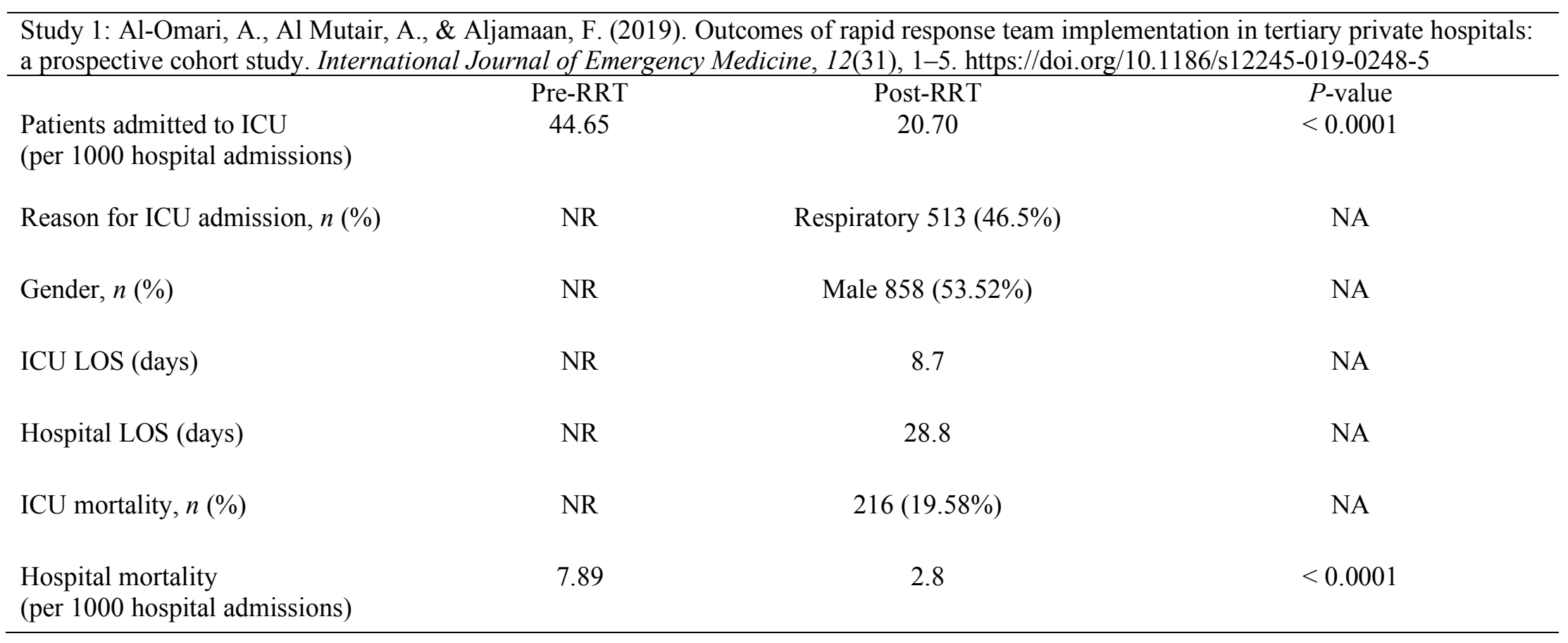

Note: $P$ values less than or equal to 0.05 were considered to be statistically significant. RRT-rapid response team, ICU-intensive care unit, LOSlength of stay, NA-not applicable, NR-not reported 
Table B-2

\section{Appendix B}

Outcome Data Collection

\begin{tabular}{|c|c|c|c|}
\hline \multicolumn{4}{|c|}{$\begin{array}{l}\text { Study 2: Jäderling, G., Bell, M., Martling, C.-R., Ekbom, A., Bottai, M., \& Konrad, D. (2013). ICU Admitta } \\
\text { Versus Conventional Admittance, Characteristics, and Outcome*. Critical Care Medicine, 41(3), 725-731. } \\
\text { https://doi.org/10.1097/ccm.0b013e3182711b94 }\end{array}$} \\
\hline & Conventional ICU & RRT ICU Admission & $P$-value \\
\hline & Admission & & \\
\hline Patients admitted to ICU & 339 & 355 & NR \\
\hline Reason for ICU admission, $n(\%)$ & Respiratory failure, 28 (8.3) & Severe sepsis, 65 (18.3) & NR \\
\hline Age, median (IQR) & $58(41-71)$ & $65(56-75)$ & $<0.01$ \\
\hline Gender, $\%$ female & 49.6 & 38 & $<0.01$ \\
\hline APACHE II score, median (IQR) & $21(14-28)$ & $26(20-31)$ & $<0.01$ \\
\hline ICU LOS, days median (IQR) & $1.2(0.6-3.3)$ & $2.0(0.9-5.5)$ & $<0.01$ \\
\hline Hospital LOS, days median (IQR) & $12.5(6-27.5)$ & $18(9-32)$ & $<0.01$ \\
\hline Mortality in the ICU, $n(\%)$ & $29(8.9)$ & $46(14.5)$ & 0.04 \\
\hline
\end{tabular}

Note: IQR-interquartile range, RRT-rapid response team, ICU-intensive care unit, APACHE- acute physiology and chronic health evaluation, LOS-length of stay, NA-not applicable, NR-not reported 
Table B-3

\section{Appendix B}

Outcome Data Collection

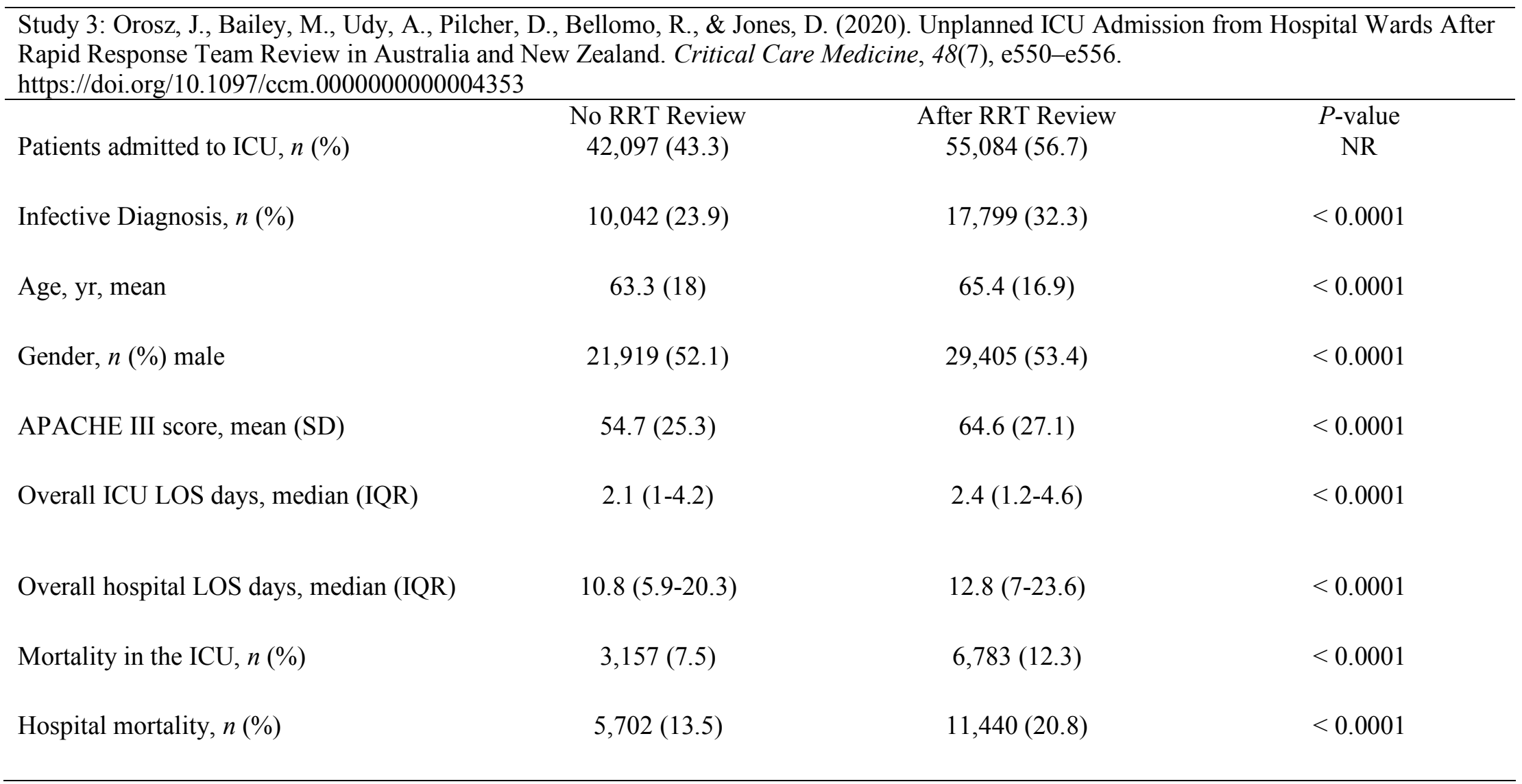

Note: A two-sided $p$ value of 0.01 was considered to be statistically significant. IQR-interquartile range, RRT-rapid response team, ICU-intensive care unit, LOS-length of stay, APACHE- acute physiology and chronic health evaluation 
Table B-4

\section{Appendix B}

Outcome Data Collection

\begin{tabular}{|c|c|c|c|}
\hline \multicolumn{4}{|c|}{$\begin{array}{l}\text { Study 4: Karpman, C., Keegan, M. T., Jensen, J. B., Bauer, P. R., Brown, D. R., \& Afessa, B. (2013). The Impact of Rapid Response Team } \\
\text { on Outcome of Patients Transferred from the Ward to the ICU. Critical Care Medicine, 41(10), 2284-2291. } \\
\text { https://doi.org/10.1097/ccm.0b013e318291cced }\end{array}$} \\
\hline & Pre-RRT & RRT & $P$-value \\
\hline Patients admitted to ICU from ward, $n(\%)$ & $2,466(23)$ & $2,424(24.1)$ & 0.066 \\
\hline Reason for ICU admission, $n(\%)$ & Respiratory, 916 (37.1) & Respiratory, 914 (37.7) & 0.022 \\
\hline Age, mean (SD) & $66.0(16.7)$ & $66.7(16.5)$ & 0.131 \\
\hline Gender, $n(\%)$ female & $1,156(46.9)$ & $1,088(44.9)$ & 0.162 \\
\hline APACHE III score, median (IQR) & $59.0(44.0-77.0)$ & $58.0(43.0-74.0)$ & 0.018 \\
\hline ICU LOS, median (IQR), days & $3(2-5)$ & $3(2-4)$ & $<0.001$ \\
\hline Hospital LOS, median (IQR), days & $11(6-22)$ & $11(6-21)$ & 0.337 \\
\hline ICU mortality, $n(\%)$ & $259(10.5)$ & $247(10.2)$ & 0.719 \\
\hline Hospital mortality, $n(\%)$ & $478(19.4)$ & $507(20.9)$ & 0.182 \\
\hline
\end{tabular}

Note: $P$ values less than 0.05 were considered to be statistically significant. IQR-interquartile range, RRT-rapid response team, ICU-intensive care unit, LOS-length of stay, APACHE-acute physiology and chronic health evaluation 
Table B-5

\section{Appendix B}

Outcome Data Collection

Study 5: Joshi, K., Campbell, V., Landy, M., Anstey, C. M., \& Gooch, R. (2017). The Effect of Rapid Response System Revision on Standard and Specific Intensive Care Unit Outcomes in a Regional Hospital. Anaesthesia and Intensive Care, 45(3), 369-374.

https://doi.org/10.1177/0310057x1704500313

Patients admitted to ICU from ward, $n$

\section{Pre-RRS Revision}

181

64.1

97 (53.6)

$21(17-27)$

68 (52-91)

$4(2,7)$

5.65

25 (13.7)

37 (20.4)
Post-RRS Revision

239

64.3

147 (56.9)

17 (13-22)

$64(43-78)$

$3(2,6)$

4.93

$33(13.8)$

$50(20.9)$
$P$-value

0.11

0.82

0.11

$<0.001$

0.011

0.02

$<0.001$

0.93

0.93

Note: $P$ values less than 0.05 were considered to be statistically significant. IQR-interquartile range, RRS-rapid response system, ICU-intensive care unit, LOS-length of stay, NA-not applicable, NR-not reported 


\section{Appendix C}

Table C-1

Critical Appraisal Skills Programme (CASP) Cohort Study Checklist

Study 1: Al-Omari, A., Al Mutair, A., \& Aljamaan, F. (2019). Outcomes of rapid response team implementation in tertiary private hospitals: a prospective cohort study. International Journal of Emergency Medicine, 12(31), 1-5. https://doi.org/10.1186/s12245-019-0248-5

\section{A) Are the results of the trial valid?}

1. Did the study address a clearly focused issue?

2. Was the cohort recruited in an acceptable way?

3. Was the exposure accurately measured to minimise bias?

4. Was the outcome accurately measured to minimise bias?

5. (a) Have the authors identified all important confounding factors?

5. (b) Have they taken account of the confounding factors in the design and/or analysis?

6. (a) Was the follow up of subjects complete enough?

6. (b) Was the follow up of subjects long enough?

\section{B) What are the results?}

7. What are the results of this study?

8. How precise are the results?

9. Do you believe the results?

C) Will the results help locally?

10. Can the results be applied to the local population? 11. Do the results of this study fit with other available evidence?

12. What are the implications of this study for practice?

\section{YES CAN'T TELL NO}

$\mathrm{X}$

$\mathrm{X}$

$\mathrm{X}$

$\mathrm{X}$

$\mathrm{X}$

$\mathrm{X}$

$\mathrm{X}$

$\mathrm{X}$

Post-RRT implementation: decreased ICU admissions, average ICU LOS 8.7 days, average hospital LOS 28.8 days, ICU mortality $19.58 \%$. Pre-RRT hospital mortality 7.89 per 1000 admissions, postRRT mortality 2.8 per 1000 admissions.

Statistically significant $p$ values for ICU admission and hospital mortality. No $p$ values reported for average LOS and ICU mortality.

$\mathrm{X}$

YES CAN'T TELL NO

$\mathrm{X}$

X

X 


\section{Appendix C}

Table C-2

Critical Appraisal Skills Programme (CASP) Cohort Study Checklist

Study 2: Jäderling, G., Bell, M., Martling, C.-R., Ekbom, A., Bottai, M., \& Konrad, D. (2013). ICU

Admittance by a Rapid Response Team Versus Conventional Admittance, Characteristics, and

Outcome*. Critical Care Medicine, 41(3), 725-731. https://doi.org/10.1097/ccm.0b013e3182711b94

\section{A) Are the results of the trial valid?}

1. Did the study address a clearly focused issue?

2. Was the cohort recruited in an acceptable way?

3. Was the exposure accurately measured to minimise bias?

4. Was the outcome accurately measured to minimise bias?

5. (a) Have the authors identified all important confounding factors?

5. (b) Have they taken account of the confounding factors in the design and/or analysis?

6. (a) Was the follow up of subjects complete enough?

6. (b) Was the follow up of subjects long enough?

\section{B) What are the results?}

7. What are the results of this study?

8. How precise are the results?

9. Do you believe the results?

C) Will the results help locally?

10. Can the results be applied to the local population? 11. Do the results of this study fit with other available evidence?

12. What are the implications of this study for practice?

\section{YES CAN'T TELL NO}

$\mathrm{X}$

$\mathrm{X}$

$\mathrm{X}$

$\mathrm{X}$

$\mathrm{X}$

X

$\mathrm{X}$

$\mathrm{X}$

Post-RRT implementation: more ICU admissions, higher APACHE II score, longer ICU and hospital LOS, higher ICU mortality.

Statistically significant $p$ values

X

YES CAN'T TELL NO

$\mathrm{X}$

$\mathrm{X}$

X 


\section{Appendix C}

Table C-3

Critical Appraisal Skills Programme (CASP) Cohort Study Checklist

Study 3: Orosz, J., Bailey, M., Udy, A., Pilcher, D., Bellomo, R., \& Jones, D. (2020). Unplanned ICU Admission from Hospital Wards After Rapid Response Team Review in Australia and New Zealand. Critical Care Medicine, 48(7), e550-e556. https://doi.org/10.1097/ccm.0000000000004353

\section{A) Are the results of the trial valid?}

1. Did the study address a clearly focused issue?

2. Was the cohort recruited in an acceptable way?

3. Was the exposure accurately measured to minimise bias?

4. Was the outcome accurately measured to minimise bias?

5. (a) Have the authors identified all important confounding factors?

5. (b) Have they taken account of the confounding factors in the design and/or analysis?

6. (a) Was the follow up of subjects complete enough?

6. (b) Was the follow up of subjects long enough?

\section{B) What are the results?}

7. What are the results of this study?

8. How precise are the results?

9. Do you believe the results?

C) Will the results help locally?

10. Can the results be applied to the local population? 11. Do the results of this study fit with other available evidence?

12. What are the implications of this study for practice?

\section{YES CAN'T TELL NO}

$\mathrm{X}$

$\mathrm{X}$

$\mathrm{X}$

$\mathrm{X}$

$\mathrm{X}$

$\mathrm{X}$

$\mathrm{X}$

$\mathrm{X}$

Post-RRT implementation: more ICU admissions, higher APACHE III score, longer ICU and hospital median LOS, higher ICU and hospital mortality rate.

Statistically significant $p$ values

$\mathrm{X}$

YES CAN'T TELL NO

$\mathrm{X}$

X

$\mathrm{X}$ 


\section{Appendix C}

Table C-4

Critical Appraisal Skills Programme (CASP) Cohort Study Checklist

Study 4: Karpman, C., Keegan, M. T., Jensen, J. B., Bauer, P. R., Brown, D. R., \& Afessa, B. (2013).

The Impact of Rapid Response Team on Outcome of Patients Transferred from the Ward to the ICU.

Critical Care Medicine, 41(10), 2284-2291. https://doi.org/10.1097/ccm.0b013e318291 cccd

\section{A) Are the results of the trial valid?}

1. Did the study address a clearly focused issue?

2. Was the cohort recruited in an acceptable way?

3. Was the exposure accurately measured to minimise bias?

4. Was the outcome accurately measured to minimise bias?

5. (a) Have the authors identified all important confounding factors?

5. (b) Have they taken account of the confounding factors in the design and/or analysis?

6. (a) Was the follow up of subjects complete enough?

6. (b) Was the follow up of subjects long enough?

\section{B) What are the results?}

7. What are the results of this study?

8. How precise are the results?

9. Do you believe the results?

C) Will the results help locally?

10. Can the results be applied to the local population? 11. Do the results of this study fit with other available evidence?

12. What are the implications of this study for practice?

\section{YES CAN'T TELL NO}

$\mathrm{X}$

$\mathrm{X}$

$\mathrm{X}$

$\mathrm{X}$

$\mathrm{X}$

$\mathrm{X}$

$\mathrm{X}$

$\mathrm{X}$

No significant difference in outcomes between pre-RRT and post-RRT period.

$P$ values not statistically significant.

X

YES CAN'T TELL NO

$\mathrm{X}$

X

X 


\section{Appendix C}

Table C-5

Critical Appraisal Skills Programme (CASP) Cohort Study Checklist

Study 5: Joshi, K., Campbell, V., Landy, M., Anstey, C. M., \& Gooch, R. (2017). The Effect of Rapid Response System Revision on Standard and Specific Intensive Care Unit Outcomes in a Regional Hospital. Anaesthesia and Intensive Care, 45(3), 369-374.

https://doi.org/10.1177/0310057x1704500313

\section{A) Are the results of the trial valid?}

1. Did the study address a clearly focused issue?

2. Was the cohort recruited in an acceptable way?

3. Was the exposure accurately measured to minimise bias?

4. Was the outcome accurately measured to minimise bias?

5. (a) Have the authors identified all important confounding factors?

5. (b) Have they taken account of the confounding factors in the design and/or analysis?

6. (a) Was the follow up of subjects complete enough?

6. (b) Was the follow up of subjects long enough?

\section{B) What are the results?}

7. What are the results of this study?

8. How precise are the results?

9. Do you believe the results?

C) Will the results help locally?

10. Can the results be applied to the local population? 11. Do the results of this study fit with other available evidence?

12. What are the implications of this study for practice?

\section{YES CAN'T TELL NO}

$\mathrm{X}$

$\mathrm{X}$

$\mathrm{X}$

$\mathrm{X}$

$\mathrm{X}$

$\mathrm{X}$

$\mathrm{X}$

$\mathrm{X}$
Post-RRS revision: more patients were admitted to the ICU with lower APACHE II and APACHE III scores, higher ICU and hospital mortality and no significant difference in ICU and hospital LOS.

Statistically significant $p$ values for APACHE II and APACHE III scores, ICU and hospital LOS.

$\mathrm{X}$

YES CAN'T TELL NO

X

$\mathrm{X}$

$\mathrm{X}$ 
Cross Study Analysis

Appendix D

\begin{tabular}{|c|c|c|c|c|c|}
\hline $\begin{array}{l}\text { Author, } \\
\text { Year }\end{array}$ & $\begin{array}{l}\text { Impact of RRT on } \\
\text { ICU admissions }\end{array}$ & $\begin{array}{l}\text { Outcome: } \\
\text { Patients admitted to } \\
\text { ICU (n) }\end{array}$ & $\begin{array}{l}\text { Outcome: } \\
\text { APACHE score }\end{array}$ & $\begin{array}{l}\text { Outcome: } \\
\text { Length of Stay } \\
\text { (days) }\end{array}$ & $\begin{array}{l}\text { Outcome: } \\
\text { Mortality } \\
(\%) \\
\end{array}$ \\
\hline $\begin{array}{l}\text { Study } 1 \\
\text { (Al-Omari et } \\
\text { al., 2019) }\end{array}$ & $\begin{array}{l}\text { Evaluated and } \\
\text { compared pre-RRT } \\
\text { and post-RRT } \\
\text { implementation on } \\
\text { number of ICU } \\
\text { admissions and } \\
\text { mortality rate. }\end{array}$ & $\begin{array}{l}1,103 \text { of } 1,603 \text { RRT } \\
\text { patients admitted to the } \\
\text { ICU, a decrease in ICU } \\
\text { admission from } 44.65 \\
\text { pre-RRT to } 20.70 \text { per } \\
1000 \text { hospital admissions } \\
\text { post-RRT. }\end{array}$ & Not measured. & $\begin{array}{l}\text { Patients admitted to the ICU } \\
\text { after RRT had an average } \\
\text { ICU LOS of } 8.7 \text { days and an } \\
\text { average hospital LOS of } 28.8 \\
\text { days. Pre-RRT data was not } \\
\text { reported for comparison. }\end{array}$ & $\begin{array}{l}\text { The overall ICU } \\
\text { mortality post-RRT } \\
\text { was } 19.58 \% \text {. Total } \\
\text { hospital mortality } \\
\text { post-RRT decreased } \\
\text { compared to pre- } \\
\text { RRT, from } 7.89 \text { to } \\
2.8 \text { per } 1000 \text { hospital } \\
\text { admissions. }\end{array}$ \\
\hline $\begin{array}{l}\text { Study } 2 \\
\text { (Jäderling et } \\
\text { al., 2013) }\end{array}$ & $\begin{array}{l}\text { Evaluated and } \\
\text { compared } \\
\text { characteristics and } \\
\text { outcomes of ICU } \\
\text { patients admitted } \\
\text { from general wards } \\
\text { based on mode of } \\
\text { admittance, via } \\
\text { RRT or } \\
\text { conventional } \\
\text { contact. }\end{array}$ & $\begin{array}{l}339 \text { conventional ICU } \\
\text { admissions and } 355 \text { via } \\
\text { the RRT. }\end{array}$ & $\begin{array}{l}\text { Patients admitted to } \\
\text { the ICU after RRT } \\
\text { demonstrated a } \\
\text { higher APACHE II } \\
\text { scores, IQR } 26 \text { vs } \\
21 \text { for conventional } \\
\text { admission. }\end{array}$ & $\begin{array}{l}\text { Patients admitted to the ICU } \\
\text { after RRT had a longer ICU } \\
\text { LOS compared to } \\
\text { conventional admissions ( } 2.0 \\
\text { days vs } 1.2 \text { days) and a longer } \\
\text { hospital LOS (18 days vs } \\
12.5) \text {. }\end{array}$ & $\begin{array}{l}\text { There was a higher } \\
\text { ICU mortality in } \\
\text { patients admitted via } \\
\text { RRT than those } \\
\text { admitted } \\
\text { conventionally } \\
(14.5 \% \text { vs } 8.9 \%) \text {. }\end{array}$ \\
\hline $\begin{array}{l}\text { Study } 3 \\
\text { (Orosz et al., } \\
2020)\end{array}$ & $\begin{array}{l}\text { Evaluated what } \\
\text { proportion of } \\
\text { unplanned ICU } \\
\text { admissions from } \\
\text { hospital wards } \\
\text { occurred after RRT } \\
\text { review. Compared } \\
\text { baseline } \\
\text { characteristics and } \\
\text { outcomes of }\end{array}$ & $\begin{array}{l}55,084 \text { admitted to the } \\
\text { ICU after RRT review } \\
\text { and } 42,097 \text { admitted } \\
\text { without RRT review. }\end{array}$ & $\begin{array}{l}\text { Patients admitted to } \\
\text { the ICU after RRT } \\
\text { review had a higher } \\
\text { APACHE III score } \\
\text { with a mean (SD) } \\
\text { of } 64.6 \text { compared } \\
\text { to } 54.7 \text { in patients } \\
\text { admitted without } \\
\text { RRT review. }\end{array}$ & $\begin{array}{l}\text { Patients admitted to the ICU } \\
\text { following an RRT had an } \\
\text { overall longer median ICU } \\
\text { LOS of } 2.4 \text { vs } 2.1 \text {. Patients } \\
\text { admitted to the ICU after } \\
\text { RRT review had a longer } \\
\text { median hospital LOS of } 12.8 \\
\text { vs } 10.8 \text { in patients admitted } \\
\text { without RRT. }\end{array}$ & $\begin{array}{l}\text { The ICU mortality } \\
\text { rate was higher in } \\
\text { patients admitted } \\
\text { after RRT review } \\
(12.3 \% \text { vs } 7.5 \%) \text {. } \\
\text { The hospital } \\
\text { mortality rate was } \\
\text { higher in patients } \\
\text { admitted to the ICU }\end{array}$ \\
\hline
\end{tabular}




\begin{tabular}{|c|c|c|c|c|c|}
\hline & $\begin{array}{l}\text { patients admitted } \\
\text { after RRT review } \\
\text { with non-RRT. }\end{array}$ & & & & $\begin{array}{l}\text { after RRT review } \\
\text { (20.8\% vs } 13.5 \%) \text {. }\end{array}$ \\
\hline $\begin{array}{l}\text { Study } 4 \\
\text { (Karpman et } \\
\text { al., 2013) }\end{array}$ & $\begin{array}{l}\text { Evaluated the } \\
\text { impact of RRT } \\
\text { implementation on } \\
\text { outcomes of } \\
\text { patients transferred } \\
\text { from the regular } \\
\text { hospital ward and } \\
\text { non-ward locations } \\
\text { to the ICU. } \\
\text { Compared } \\
\text { characteristics and } \\
\text { outcomes of } \\
\text { patients pre-RRT } \\
\text { and post RRT- } \\
\text { implementation. }\end{array}$ & $\begin{array}{l}2,466 \text { patients admitted } \\
\text { during the pre-RRT } \\
\text { period and } 2,424 \text { patients } \\
\text { admitted to the ICU } \\
\text { from the wards during } \\
\text { the RRT period. }\end{array}$ & $\begin{array}{l}\text { Patients admitted to } \\
\text { the ICU from the } \\
\text { wards in the RRT } \\
\text { period } \\
\text { demonstrated a } \\
\text { lower APACHE III } \\
\text { score than the pre- } \\
\text { RRT period, } 58 \text { vs } \\
59 \text { respectively. }\end{array}$ & $\begin{array}{l}\text { The median ICU and hospital } \\
\text { LOS were the same for both } \\
\text { groups, } 3 \text { and } 11 \text { days } \\
\text { respectively. }\end{array}$ & $\begin{array}{l}\text { ICU Mortality was } \\
\text { lower for patients in } \\
\text { the RRT group vs } \\
\text { patients in the pre- } \\
\text { RRT group. (10.2\% } \\
\text { vs } 10.5 \%) \text {. Hospital } \\
\text { mortality was higher } \\
\text { in the RRT group } \\
\text { compared to the pre- } \\
\text { RRT group ( } 20.9 \% \\
\text { vs } 19.4 \%) \text {. }\end{array}$ \\
\hline $\begin{array}{l}\text { Study } 5 \\
\text { (Joshi et al., } \\
2017 \text { ) }\end{array}$ & $\begin{array}{l}\text { Evaluated the } \\
\text { impact of an Adult } \\
\text { Deterioration } \\
\text { Detection System } \\
\text { (Q-ADDS)-based } \\
\text { RRS on illness } \\
\text { severity at ICU } \\
\text { admission and ICU } \\
\text { LOS. }\end{array}$ & $\begin{array}{l}181 \text { patients admitted to } \\
\text { the ICU from the ward } \\
\text { in the pre-RRS revision } \\
\text { period and } 239 \text { patients } \\
\text { were admitted in the } \\
\text { post-RRS revision } \\
\text { period. }\end{array}$ & $\begin{array}{l}\text { Reduction in } \\
\text { median APACHE } \\
\text { II scores in the } \\
\text { post-RRS revision } \\
\text { period (17 vs 21). } \\
\text { Reduction in } \\
\text { median APACHE } \\
\text { III scores in the } \\
\text { post-RRS revision } \\
\text { period compared to } \\
\text { the pre-RRS } \\
\text { revision period (64 } \\
\text { vs } 68 \text { ). }\end{array}$ & $\begin{array}{l}\text { There was a reduction in } \\
\text { median ICU LOS in the post- } \\
\text { RRS revision period ( } 3 \text { vs } 4) \text {. } \\
\text { As well as a reduction in the } \\
\text { median hospital LOS in the } \\
\text { post-RRS revision period } \\
(4.93 \text { vs } 5.65) \text {. }\end{array}$ & $\begin{array}{l}\text { Median ICU } \\
\text { mortality was higher } \\
\text { in the post-RRS } \\
\text { revision period } \\
13.8 \% \text { vs } 13.7 \% \text {. } \\
\\
\text { Median hospital } \\
\text { mortality was higher } \\
\text { in the post-RRS } \\
\text { revision period } \\
20.9 \% \text { vs } 20.4 \% \text {. }\end{array}$ \\
\hline
\end{tabular}

